
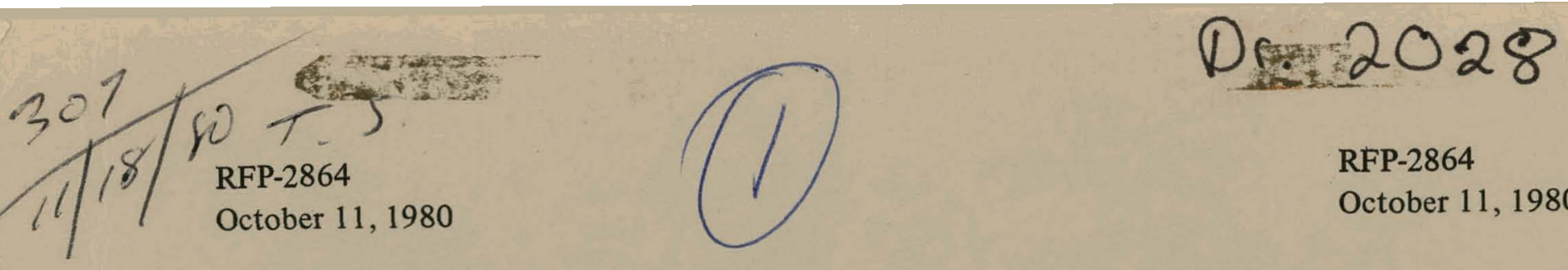

RFP-2864

October 11, 1980

Metuce

PORTIONS OF THIS REPGFT ARE ULLGTBLE.

It has been reproduced from the hest available copy to permit the broadest possible availability.

\title{
LITERATURE ON FABRICATION OF
}

TUNGSTEN FOR APPLICATION IN

PYROCHEMICAL PROCESSING OF SPENT NUCLEAR FUELS

Carl M. Edstrom

Alan G. Phillips

Lytle D. Johnson

Richard R. Corle

\section{MASTER}

cp

Rockwell International

\footnotetext{
Energy Systems Group

Rocky Flats Plant

P.O. Box 464

Golden, Colorado 80401
}

U. S. DEPARTMENT OF ENERGY CONTRACT DE-AC04-76DPO3533 


\section{DISCLAIMER}

This report was prepared as an account of work sponsored by an agency of the United States Government. Neither the United States Government nor any agency Thereof, nor any of their employees, makes any warranty, express or implied, or assumes any legal liability or responsibility for the accuracy, completeness, or usefulness of any information, apparatus, product, or process disclosed, or represents that its use would not infringe privately owned rights. Reference herein to any specific commercial product, process, or service by trade name, trademark, manufacturer, or otherwise does not necessarily constitute or imply its endorsement, recommendation, or favoring by the United States Government or any agency thereof. The views and opinions of authors expressed herein do not necessarily state or reflect those of the United States Government or any agency thereof. 


\section{DISCLAIMER}

Portions of this document may be illegible in electronic image products. Images are produced from the best available original document. 
This report was prepared as an account of work sponsored by an agency of the United States Government. Neither the United States Government nor any agency thereof, nor any of their employees, makes any warranty, express or implied, or assumes any legal liability or responsibility for the accuracy, completeness, or usefulness of any information, apparatus, product, or process disclosed, or represents that its use would not infringe privately owned rights. Reference herein to any specific commercial product, process, or service by trade name, trademark, manufacturer, or otherwise, does not necessarily constitute or imply its endorsement, recommendation, or favoring by the United States Government or any agency thereof. The views and opinions of authors expressed herein do not necessarily state or reflect those of the United States Government or any agency thereof.

Printed in the United States of America Available from the

National Technical Information Service

U.S. Department of Commerce Springfield, Virginia 22161

Page Range

Domestic Price*

001-025

$\$ 5.00$

026-050

6.00

051-075

7.00

076-100

8.00

*All microfiche are priced at $\$ 3.50$

Prices Subject to Change Without Notice 
October 11, 1980

LITERATURE ON FABRICATION OF TUNGSTEN FOR APPLICATION IN PYROCHEMICAL PROCESSING OF SPENT NUCLEAR FUELS

Carl M. Edstrom

Alan G. Phillips

Lytle D. Johnson

Richard R. Corle

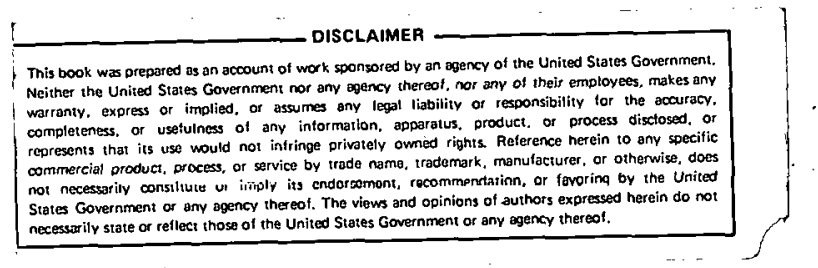

$$
\begin{gathered}
\text { ROCKWELL INTERNATIONAL } \\
\text { ENERGY SYSTEMS GROUP } \\
\text { ROCKY FLATS PLANT } \\
\text { P.O. BOX } 464
\end{gathered}
$$

GOLDEN, COLORADO 80401

\author{
Prepared under Contract DE-AC04-76DPO3533 \\ for the \\ Albuquerque Operations Office \\ U.S. Department of Energy
}




\section{CONTENT S}

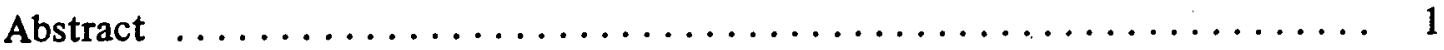

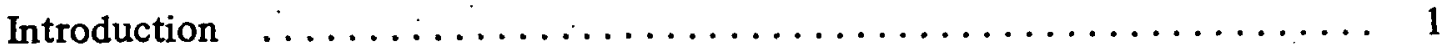

Background $\ldots \ldots \ldots \ldots \ldots \ldots \ldots \ldots \ldots \ldots \ldots \ldots \ldots \ldots \ldots \ldots \ldots \ldots \ldots \ldots$

Tungsten Production $\ldots \ldots \ldots \ldots \ldots \ldots \ldots \ldots \ldots \ldots \ldots \ldots \ldots \ldots$

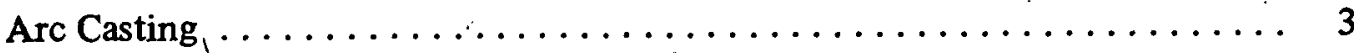

Electrowon $\ldots \ldots \ldots \ldots \ldots \ldots \ldots \ldots \ldots \ldots \ldots \ldots \ldots \ldots \ldots \ldots \ldots, 3$

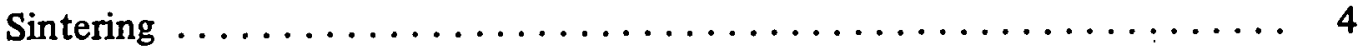

Factors Influencing Tungsten Ductility $\ldots \ldots \ldots \ldots \ldots \ldots \ldots \ldots \ldots \ldots$

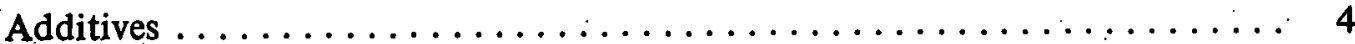

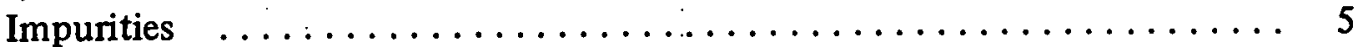

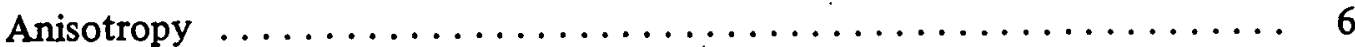

Cold Work $\ldots \ldots \ldots \ldots \ldots \ldots \ldots \ldots \ldots \ldots \ldots \ldots \ldots \ldots \ldots$

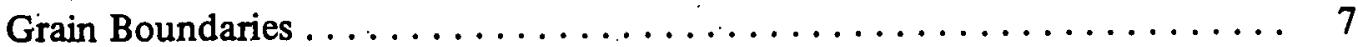

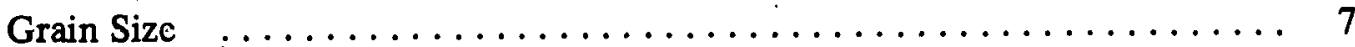

Annealing or Stress Relieving $\ldots \ldots \ldots \ldots \ldots \ldots \ldots \ldots \ldots \ldots$

Heat Treating $\ldots \ldots \ldots \ldots \ldots \ldots \ldots \ldots \ldots \ldots \ldots \ldots \ldots \ldots$

Recrystallization $\ldots \ldots \ldots \ldots \ldots \ldots \ldots \ldots \ldots \ldots \ldots \ldots \ldots \ldots$

Ductile-Brittle Transition Temperatures $\ldots \ldots \ldots \ldots \ldots \ldots \ldots \ldots$

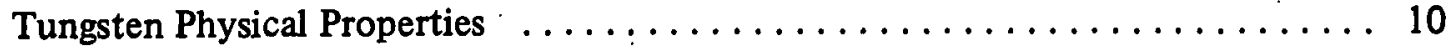

Physical Properties $\ldots \ldots \ldots \ldots \ldots \ldots \ldots \ldots \ldots \ldots \ldots \ldots \ldots \ldots \ldots$

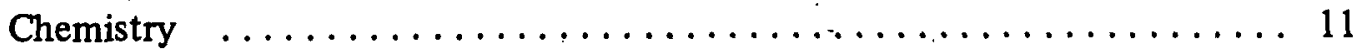

Tungsten Fabrication $\ldots \ldots \ldots \ldots \ldots \ldots \ldots \ldots \ldots \ldots \ldots \ldots \ldots \ldots \ldots$

Sintered Crucible $\ldots \ldots \ldots \ldots \ldots \ldots \ldots \ldots \ldots \ldots \ldots \ldots \ldots \ldots \ldots$ 


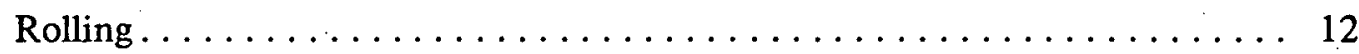

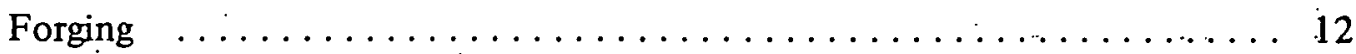

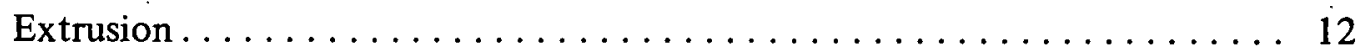

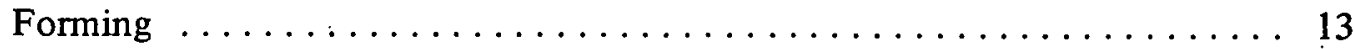

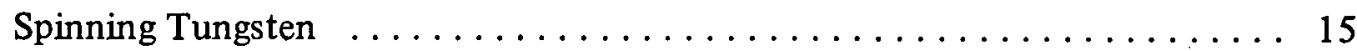

Spinning- - General Practice $\ldots \ldots \ldots \ldots \ldots \ldots \ldots \ldots \ldots \ldots \ldots$

Ring Rolling. . . . . . . . . . . . . . . . . . . . 18

Explosive Forming $\ldots \ldots \ldots \ldots \ldots \ldots \ldots \ldots \ldots \ldots \ldots$

Exotic Forming $\ldots \ldots \ldots \ldots \ldots \ldots \ldots \ldots \ldots \ldots \ldots \ldots \ldots \ldots$

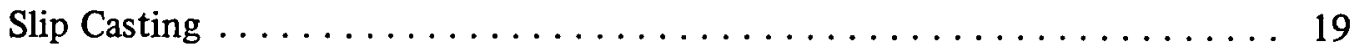

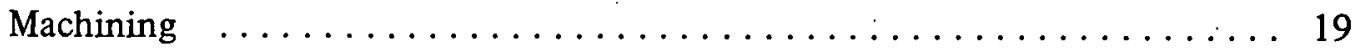

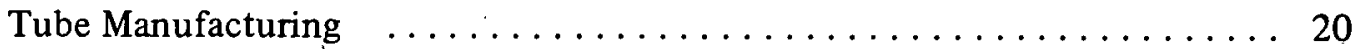

Product Availability . . . . . . . . . . . . . . . . . . . 22

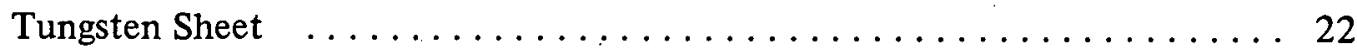

Crucible Size $\ldots \ldots \ldots \ldots \ldots \ldots \ldots \ldots \ldots \ldots \ldots \ldots \ldots \ldots \ldots \ldots$

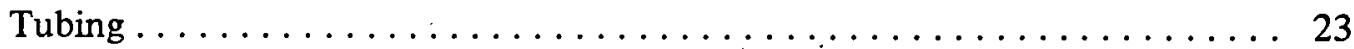

Joining of Tungsten $\ldots \ldots \ldots \ldots \ldots \ldots \ldots \ldots \ldots \ldots \ldots \ldots \ldots \ldots \ldots$

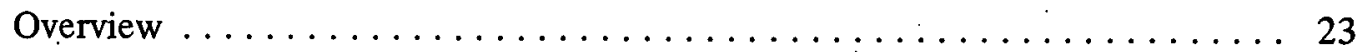

Background $\ldots \ldots \ldots \ldots \ldots \ldots \ldots \ldots \ldots \ldots \ldots \ldots \ldots \ldots \ldots \ldots \ldots$

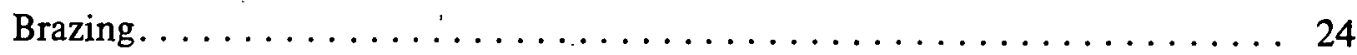

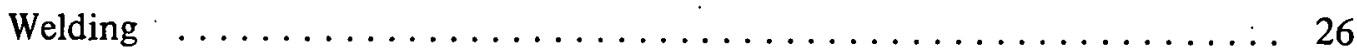

Other Joining Processes $\ldots \ldots \ldots \ldots \ldots \ldots \ldots \ldots \ldots \ldots \ldots$

Chemical Vapor Deposited Tungsten $\ldots \ldots \ldots \ldots \ldots \ldots \ldots \ldots \ldots \ldots$

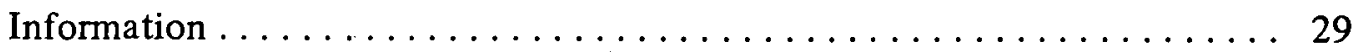




\section{RFP-2864}

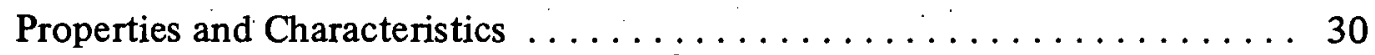

Techniques $\ldots \ldots \ldots \ldots \ldots \ldots \ldots \ldots \ldots \ldots \ldots \ldots \ldots \ldots \ldots$

Chemical Vapor Deposited Tungsten on Graphite Crucible $\quad \ldots \ldots \ldots \ldots 35$

Chemical Vapor Deposited Tungsten on Molybdenum Crucible ........ 35

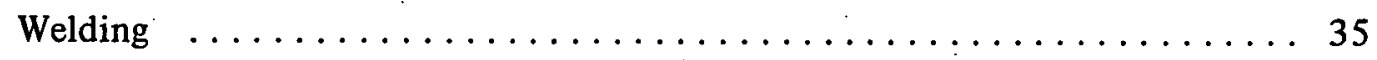

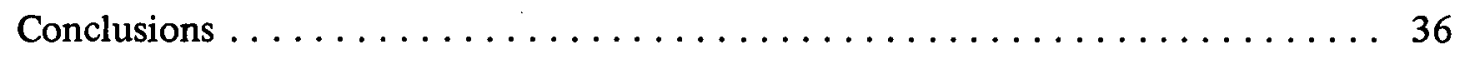

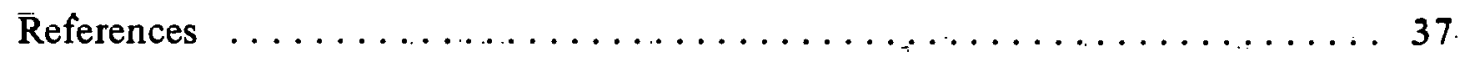




\section{LIST OF TAB LES}

1. Effect of Anneal Temperature and Different Compositions on DBTT and Recrystallization Temperature of Tungsten $\ldots \ldots \ldots \ldots \ldots$

2. Average Tensile Properties of Fansteel Tungsten Sheet $\ldots \ldots \ldots \ldots \ldots \ldots \ldots$

3. Bend Transition Temperature for Unrecrystallized Tungsten Sheet $\ldots \ldots \ldots \ldots \ldots$

4. Physical Properties of Tungsten and Molybdenum $\ldots \ldots \ldots \ldots \ldots \ldots \ldots$

5. Impurity Levels (in ppm) of Commercial Tungsten $\ldots \ldots \ldots \ldots \ldots \ldots \ldots \ldots$

6. Minimum Shearing Temperature for Tungsten $\ldots \ldots \ldots \ldots \ldots \ldots \ldots \ldots \ldots \ldots 13$

7. Tensile Data on Doped and Undoped 0.100-in.-Thick Tungsten Sheet. . . . . . 16

8. Tooling Recommendations for Tuming Tungsten and Molybdenum $\ldots \ldots \ldots 20$

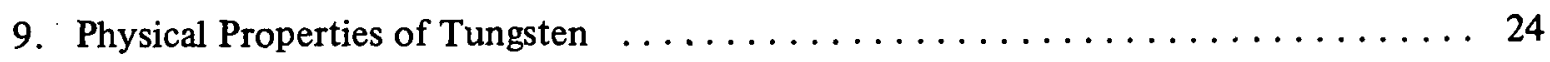

10. Brazing Alloys for Use With Tungsten $\ldots \ldots \ldots \ldots \ldots \ldots \ldots \ldots \ldots \ldots \ldots$

11. Effects of Superșaturation and Temperature on the Structure of Condensed Metals $\ldots \ldots \ldots \ldots \ldots \ldots \ldots$ 


\section{LIS T OF FIG URES}

1. Bend Transition Temperature Versus Percent Cold Work $\ldots \ldots \ldots \ldots \ldots \ldots$

2. Working Temperature for Tungsten Sheet $\ldots \ldots \ldots \ldots \ldots \ldots \ldots \ldots \ldots$

3. Dependence of Ductility on

Environmental Pressure for Tungsten Rod - Tensile Test

4. Filled-Extrusion Billet for Extruding Tungsten $-25 \%$ Rhenium Tube . . . . . . 21

5. Technique for Drawing Tube With Stationary Mandrel $\ldots \ldots \ldots \ldots \ldots \ldots 22$ 


\title{
LITERATURE ON FABRICATION OF
}

\author{
TUNGSTEN FOR APPLICATION IN \\ PYROCHEMICAL PROCESSING OF SPENT NUCLEAR FUELS
}

\author{
Carl M. Edstrom, Alan G. Phillips, Lytle D. Johnson, \\ and Richard R. Corle
}

\begin{abstract}
The pyrochemical processing of nuclear fuels requires crucibles, stirrers, and transfer tubing that will withstand the temperature and the chemical attack from molten salts and metals used in the process. This report summarizes the literature that pertains to fabricating this hardware. Tungsten fabrication (joining, chemical vapor deposition, plasma spraying, forming, and spinning) is the main theme. This report also summarizes a sampling of literature on molybdenum and the work previously performed at Argonne National Laboratory on other container materials used for pyrochemical processing of spent nuclear fuels.
\end{abstract}

\section{INTRODUCTION}

The pyrochemical processing of nuclear fuels requires crucibles, stirrers, and transfer lines that will withstand the temperature and chemical attack from molten salts and metals used in the process. Being able to fabricate the necessary hardware is critical to pyrochemical processing. Complicating this fabrication is the need in pyrochemical processing for a crucible large enough to contain the entire fuel rod (10 cu ft or more). Tungsten can withstand the temperature and chemical attack; however, it is not available in rolled sheet large enough to provide the surface area necessary for the crucibles. This dictates development in joining, coating, and forming processes to achieve the desired shape and size.

To gather as much information as possible on tungsten fabrication, a literature review has been performed. This report summarizes that literature review. It also includes background information on material evaluation performed by personnel at
Argonne National Laboratory during their pyrochemical processing experiments in the early 1960 s. Included, too, is a brief description on molybdenum, which is an excellent substrate for coating. Several of the fabrication processes for tungsten do not apply to making hardware for pyrochemical processing, but they still are reported here for general information.

\section{Background}

Kyle and his associates (1969*) propose the use of refractory metals as containment materials that will withstand exposure to pyrochemical process solvents containing fission products. These process solvents include alloys of copper, zinc, cadmium, and magnesium, in addition to salts of alkaline and alkaline earth halides, at operational temperatures from 500 to $900{ }^{\circ} \mathrm{C}$. Primarily, two phases are in contact with the container. They are as follows:

1. A metal solvent phase of copper, zinc, and cadmium with magnesium as a reducing agent

2. A molten salt solvent phase containing alkali metals and alkaline earth halides with an oxidizing agent such as $\mathrm{MgCl}_{2}$

The vessel material should then fulfill the following set of requirements towards being a suitable candidate:

1. The corrosion rate of the material should be low enough to provide an adequate service life.

2. The integrity of the vessel must be such as to be reliable during the handling of fission

*See "References," page 37. 
products, which include plutonium and uranium.

3. Limited access requires the vessel to be as maintenance-free as possible.

4. High strength of the vessel is not critical, but the vessel must be ductile enough to withstand thermal expansion and contraction.

5: The container must have a low porosity to prevent leakage of molten salt.

6. The container must withstand thermal shock.

$\%$ l' lhe container must withstand attack by a continually changing environment, where new material is constantly introduced, without allowing an equilibrium or a stagnant situation to be created.

8. The vessel must withstand degradation caused by mass transfer from a temperature or concentration gradient.

9. A large crucible must be capable of being fabricated.

A test procedure was developed by Kyle and his co-workers in which specimens are exposed to successively more stringent conditions upon positive completion of the preceding test. These tests are conducted in the following numerical order:

1. An "Isothermal Capsule Test" to expose specimens to an isothermal system

2. A "Corrosion Agitator Test" to remove nonadherent reaction films from the specimens

3. A "Crucible Test" under conditions that simulate actual use

4. A "Solution Stability Test" to test the specimen's resistance to fission products

5. A "Thermal Convection Loop Test" to determine mass transfer effects under thermal or concentration gradients

6. A "Prototype Vessel Testing" along with destructive and non-destructive examinations of the working container
Corrosion can occur by the following mechanisms:

1. The container material dissolves into the liquid metal, usually until an equilibrium is established.

2. Intergranular attack occurs by the solubility of elements concentrated at the grain boundaries or by metal phase reaction with grain boundary precipitates.

3. Moisture in the salt can form oxychlorides, hydrogen, and chlorine, all of which corrode tungsten.

4. The salt phase ran cause embrittlement of the vessel material. Tantalum is embrittled by exposure to the molten salt phase.

5. Because of its reducing nature, magnesium can be the source of corrosion, especially attacking ceramic materials such as alumina. Magnesium also attacks oxide films and is therefore harmful to metals that are dependent upon their oxide film for corrosion resistance.

Ferrous alloys were tested under pyrochemical process conditions with the following observations being made:

1. Austenitic Stainless Steels-Nickel lcaching occurs since nickel is soluble in copper, zinc, cadmium, and magnesium.

2. Ferritic Stainless Steels-Neither chrome nor iron is highly soluble in the metal phases.

However, $\mathrm{U}_{6} \mathrm{Fe}$ and $\mathrm{UFe}_{2}$ have formed under test conditions.

3. Cast Iron, Carbon Steel, Low Alloy Steel- In addition to lacking strength at test conditions, these steels form a uranium-iron intermetallic compound as well as UP or $\mathrm{U}_{3} \mathrm{P}_{4}$.

Refractory metals were assessed as follows:

1. Tungsten, tantalum, niobium, molybdenum, rhenium, and various alloy combinations show a low solubility under the process conditions and are therefore corrosion resistant.

2. Fabrication of refractory metals is difficult.

3. The more ductile materials, tantalum and niobium, are susceptible to embrittlement by 
molten salts, hydrogen. sus? axygen. Embrittlement would incs..s. . . ... : : tailure through nechanic al in i... ; ; thock.

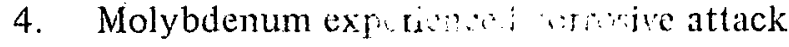
from the copper-magnesdmin wal phase.

5. Tungsten is nearly corrosion resistant under stated test conditions.

Graphite and vitreous carbon werc assessed as follows:

1. Conventional grades of graphite are too porous to contain molten salt.

2. Uranium and plutonium react with graphite to form carbides and thereby contribute to yield losses.

3. Silicon carbide coatings have been applied to graphite, but coating density is a problem.

4. Graphite has a thermal expansion coefficient range of $1 \times 10^{-6}$ to $4 \times 10^{-6} \mathrm{in} . / \mathrm{in} .{ }^{\circ} \mathrm{F}$ depending on grain orientation of the graphite. To provide a well-adhering coating of $\mathrm{SiC}$ or tungsten on a graphite substrate, a graphite material such as Speer SX-4 must be chosen. The material's characteristics should match the isotropic thermal expansion characteristics of either tungsten or $\mathrm{SiC}$, which have expansion coefficients of about $2.2 \times 10^{-6} \mathrm{in} . / \mathrm{in} .{ }^{\circ} \mathrm{F}$.

Silicon carbide and alumina were assessed as follows:

1. Silicon carbide is inert to process solutions.

2. Standard-density $\mathrm{SiC}$ parts are too porous to contain molten salts.

3. High-density $\mathrm{SiC}$ is susceptible to thermal shock.

4. Alumina, like $\mathrm{BN}$ crucibles, is reduced by molten magnesium.

5. Zirconia and magnesia vessels would be too porous (Kyle-1969).

\section{TUNGSTEN PRODUCTION}

\section{Arc Casting}

The arc-casting process was developed for molybdenum. Molybdenum ingots up to $16 \mathrm{in}$. in diameter and weighing $4000 \mathrm{lb}$ have been melted, extrucied, and fabricated. The arc-cast ingots must be extruded prior to any other type of working because both the large grain and the hot shortness cause fracture in any process that does not fully contain the metal.

Because electrical power is the only limit on arccast ingot size, the arc-casting process offers the best possibility of producing large refractory metal ingots. With tungsten, however, the limiting factor is not ingot size; it is the fabricating equipment. In 1960, fast-acting extrusion presses were available to extrude 12-in.-dia tungsten; however, the heating facilities, in conjunction with these large extrusion presses, did not have the temperature capability required (Jaffee).

Casting tungsten involves another problem, which centers around finding acceptable mold material. Molds made of graphite work, but the metal-mold interaction is severe and 0.32 to $0.48 \mathrm{~cm}$ of the metal's surface thickness must be removed to get below the affected metal (Wilkinson-1970).

Extrusion yields can be looked upon as an insight into the ductility of the material, at least at the temperature of extrusion. Low-carbon, unalloyed, arc-cast tungsten cannot be successfully extruded at temperatures in the range of 2200 to $2600^{\circ} \mathrm{F}$. However, low-carbon, arc-cast tungsten with additions of $3.72 \%$ molybdenum can be successfully extruded at 2400 and $2600^{\circ} \mathrm{F}$ (Barr).

\section{Electrowon}

Keith (1970) identifies electrowon tungsten powder as that produced by fused-salt electrolysis techniques. Tungsten powder produced by the electrolysis process is acicular crystals, approximately $74 \mu \mathrm{m}$ in size. This compares to 2 to $5 \mu \mathrm{m}$ for commercially produced tungsten powder made through hydrogen reduction of tungsten ore. The larger particles of electrowon tungsten are less contaminated with oxygen than commercially produced powder and should therefore be more ductile. This improved ductility was not demonstrated through experiments because the larger particle size powder did not produce material as dense as that obtained through 
conventional sintering. Experiments with sheath rolling and swaging, high-energy-rate extrusion, and hot pressing were all designed to densify the electrowon tungsten crystals. Keith and his coworkers successfully increased the density but did not produce a material with better forming or physical properties than in conventional tungsten (Keith). The added cost of electrowon tungsten sheet is therefore not justified.

\section{Sintering}

The general technique for preparing tungsten sheet is to first press a tungsten compact. The second step is sintering. Densification is completed by mechanically working the material with a technique such as swaging. Mechanical processing is done at a temperature below the recrystallization temperature (Parks).

German and Ham describe a method for applying a coating of nickel or palladium (a 4-layer-thick coating showing a maximum effect) on tungsten grains prior to the occurrence of the sintering action. This method helps increase the efficiency of the sintering process by increasing linear shrinkage to 11.5\% (German).

Googin et al., discuss techniques for forming large tungsten bodies by isostatically forming the part, then sintering. Powder-compaction techniques that are discussed include mold material, mold construction, and formation of the body with and without a mandrel (Googin).

Dorodnyi et al., describe a process for improving the green density of a body when utilizing hydrostatic molding. The mold is vibrated while being filled with powder. This is followed by pulling a vacuum (possibly to aid in wetting by the glycerin binder) and then hydrostatic pressing. The body would then be sintered (Dorodnyi).

Annular tungsten powder (particle size between 1 and $10 \mu \mathrm{m}$ ) compacts without a binder. Finer powders form compacts of non-uniform density (Jaffec).
Adding 0.25 to $5.0 \mathrm{wt} \%$ nickel to the tungsten powder increases the as-sintered density. Up to $98 \%$ of theoretical density can be reached with. the nickel sintering aid (Jaffee, Wilkinson-1969).

Hot-pressing theoretically can increase the density of pressed tungsten; however, a die limitation prevents practical production of compacts more than $50 \mathrm{~mm}$ in diameter. Steel strength falls rapidly above $600^{\circ} \mathrm{C}$, thus limiting the pressing pressure. Graphite dies have been used up to $3000{ }^{\circ} \mathrm{C}$ and pressures to $686 \mathrm{MPa}(99,500 \mathrm{psi})$, but the die wall must be very thick. Also, excessive carburization generally occurs during hot-pressing in graphite (Jaffee, Wilkinson-1970).

\section{FACTORS INFLUENCING TUNGSTEN DUCTILITY}

\section{Additives}

The development of tungsten alloys is still limited. This is chiefly due to difficulties in the preparation and fabrication of such alloys. The fields most actively studied are

1. The improvement of mechanical properties at high temperatures

2. The improvement of ductility at low temperatures

\section{The improvement of machinability (Syre)}

Despite a very low solubility of interstitial elements in tungsten, a variety of tungsten alloys have been formulated to maximize various mechanical or physical properties (Burr). Examples of these alloys are listed in the paragraphs that follow.

A tungsten -27 wt \% rhenium alloy, as a wrought material of a fine-grained recrystallized structure, has a ductile-brittle transition temperature (DBTT) of $-47^{\circ} \mathrm{C}$ (Wilkinson-1969). Refer to "DuctileBrittle Transition Temperature," page 9, for an explanation on DBTT. According to Schmidt, tungsten -30 wt \% rhenium lowers the DBTT of tungsten several hundred degrees (Schmidt).

Rhenium, when added in sufficient quantity (26\%) to tungsten, improves high-temperature properties and at the same time improves fabricability and 
ductility. However, the high cost of rhenium handicaps the development of this alloy (Syre).

The addition of reactive metals such as titanium or zirconium, in 0.5 to $1.5 \mathrm{wt} \%$ increments, causes a reaction with interstitial impurities and thereby hinders atom movements by giving a resulting dispersed phase. The net effect is a lowering of the DBTT (Schmidt).

At $3400^{\circ} \mathrm{F}$, various alloys reduce the elongation lcvel for unalloyed tungsten from $85 \%$ to levels below $5 \%$. There are subsequent losses in ductility, however, as demonstrated by extrusion yields. The compositions of these alloys are as follows:
a. $\quad 6.5 \%$ tantalum, $0.002 \%$ carbon, balance tungsten
b. $4.8 \%$ niobium, $0.002 \%$ carbon, balance tungsten
c. $4.6 \%$ tantalum, $4.56 \%$ niobium, $0.001 \%$ carbon, balance tungsten
d. $\quad 7.0 \%$ tantalum, $6.63 \%$ niobium, $0.002 \%$ carbon, balance tungsten
e. $\quad 4.3 \%$ tantalum, $4.68 \%$ niobium, $4.63 \%$ molyb- denum, $0.001 \%$ carbon, balance tungsten

Optimum alloying additions for strength, without a severe reduction in ductility, are probably in much lower percentages than those just mentioned (Semchyshen). As a single additive in the 3 to $10 \%$ range, tantalum markedly increases high-temperature properties, but it raises the DBTT and thereby increases the difficulty of forming (Syre).

Metallic carbide formation acts to pin grain boundaries and dislocations (Semchyshen).

A tungsten $-4 \mathrm{wt} \%$ molybdenum alloy results in a small grain size with elongated grains that are parallel to the ingot.axes. A resultant decrease therefore occurs in the DBTT (Barr). Molybdenum in a tungsten alloy, at a 3 to $10 \%$ level, also has a strengthening effect (Syre).
Sodium oxide inhibits grain growth and maintains the shape of elongated grains during recrystallization up to $2700^{\circ} \mathrm{C}$.

Zirconium oxide $\left(\mathrm{ZrO}_{2}\right)$ prevents grain-boundary migration and retards recrystallization from 1000 to $2000^{\circ} \mathrm{C}$. Additions of $\mathrm{ThO}_{2}$ or $\mathrm{ZrO}_{2}$ to tungsten powder can benefit the formability of the sheet product. A comparison of the DBTT of tungsten sheet with three separate compositions, but with the same fabrication condition, is shown in Table 1.

Tungsten alloys with $\mathrm{TiN}, \mathrm{ZrN}$, or $\mathrm{TaN}$ (each at the 2 vol \% levels) retard recrystallization grain growth and raise recrystallization temperatures.

Alloys with $10 \% \mathrm{ZrO}_{2}$ or 2 vol \% colloidally dispersed $\mathrm{Al}_{2} \mathrm{O}_{3}$ or $\mathrm{ZrN}$ in tungsten powder can produce recrystallized grains small enough to measure 2000 to 4000 grains per square centimeter.

A tungsten alloy containing $5 \mathrm{wt} \%$ rhenium and 2.2 wt $\% \mathrm{ThO}_{2}$ is one of the most ductile tungsten alloys with a high recrystallization temperature and a small grain size (Wilkinson-1969).

Titanium, zirconium, hafnium, and chromium have a small range of solid solubility and quickly produce brittleness in tungsten (Syre).

The presence of $\mathrm{ZrO}_{2}$ or $\mathrm{ThO}_{2}$ lowers the transition temperature, raises the recrystallization temperature of sheet, and inhibits coarsening of the grain in high-temperature sintering. Greater than $8 \%$ by volume of $\mathrm{ZrO}_{2}$ or $\mathrm{ThO}_{2}$, however, does not provide good fabricability (Syre).

\section{Impurities}

Bechtold and Shewmon recommend high-purity tungsten to reduce the DBTT. Impurities such as carbon, phosphorus, and oxygen congregate at the grain boundaries to give an embrittling effect. Concentrations of these impurities may nucleate cracks (Bechtold). Inclusions of oxygen are more detrimental to the workability of tungsten than carbon; therefore, carbon deoxidation is utilized when processing tungsten (Barr, Schmidt, Wilkinson-1969). As an example, 3.2-mm-dia rod 
TABLE 1. Effect of Anneal Temperature and Different Compositions on DBTT* and Recrystallization Temperature of Tungsten (Syre)

\begin{tabular}{|c|c|c|c|c|c|c|}
\hline & \multicolumn{6}{|c|}{ Anneal Temperature $\left({ }^{\circ} \mathrm{C}\right)$} \\
\hline & 1200 & 1300 & 1400 & 1600 & 1800 & 2000 \\
\hline Tungsten & 205 & 200 & $310^{R}$ & $350^{\mathrm{F}}$ & 360 & 370 \\
\hline Tungsten +8 vol $\% \mathrm{ZrO}_{2}$ & 140 & 85 & 170 & $220^{R}$ & $260 \mathrm{~F}$ & 300 \\
\hline Tungsten +8 vol $\% \mathrm{ThO}_{2}$ & 150 & 80 & $90^{\mathrm{R}}$ & 180 & $270^{\mathrm{F}}$ & 300 \\
\hline
\end{tabular}

with 10-ppm oxygen has a DBTT of $660^{\circ} \mathrm{F}$. The same rod but with only $4 \mathrm{ppm}$ oxygen has a DBTT of $450^{\circ} \mathrm{F}$. (Wilkinson-1969). High oxygen content leads to a ductility reduction by segregation of oxygen at the grain boundaries; it also leads to a strength reduction (Mash).

Syre (1965) presents the following data to support the need for low levels of oxygen.

\begin{tabular}{cc}
$\mathrm{O}_{2}(\mathrm{ppm})$ & DBTT $\left({ }^{\circ} \mathrm{C}\right)$ \\
\hline 4 & 230 \\
10 & 345 \\
30 & 450 \\
50 & 550
\end{tabular}

Other data, however, indicate that the DBTT is not sensitive to 1 - to $15-\mathrm{ppm}$ oxygen, 1 - to 2 -ppm nitrogen, and 1- to 3-ppm hydrogen (Wilkinson1970).

Mash states that it is almost impossible to prevent segregation of nitrogen and oxygen at the grain boundaries by composition control alone. To keep the ductile-to-brittle temperature low, it is therefore desirable to have small elongated grains. The grain boundary volume can then be increased to accommodate nitrogen and oxygen precipitation (Mash).

Carbon up to $0.3 \%$ does not appear to affect formability or to influence the recrystallization temperature (Syre). However, all refractory metals form carbides in the presence of minutc quantities of carbon and its compounds. With tungsten, this occurs at $1000^{\circ} \mathrm{C}$; therefore, graphite fixturing should not be used to position tungsten in brazing (Pattee-1974).

Hydrogen has no appreciable effect on tungsten (Hargrave).

\section{Anisotropy}

Forming characteristics of tungsten sheet are influenccd by the degree of anisotropy, which is the difference in physical properties between the longitudinal and transverse directions (Fusco, Hegedus). Enhanced formability occurs as the degree of anisotropy is lessened. One method of accomplishing this is by cross-rolling tungsten sheet, which then minimizes anisotropy and consequently lowers the DBTT (Maykuth).

\section{Cold Work}

Cold work refers to a mechanical reduction in thickness at temperatures below the recrystallization temperature. Cold-work sheet tungsten is sensitive to the direction in which the material is worked, the method of formation having established an original work direction. As the amount of cold work is increased in the longitudinal direction, the DBTT is decreased continuously in this direction. But, as this cold work is performed in the longitudinal direction, the DBTT in the transverse 


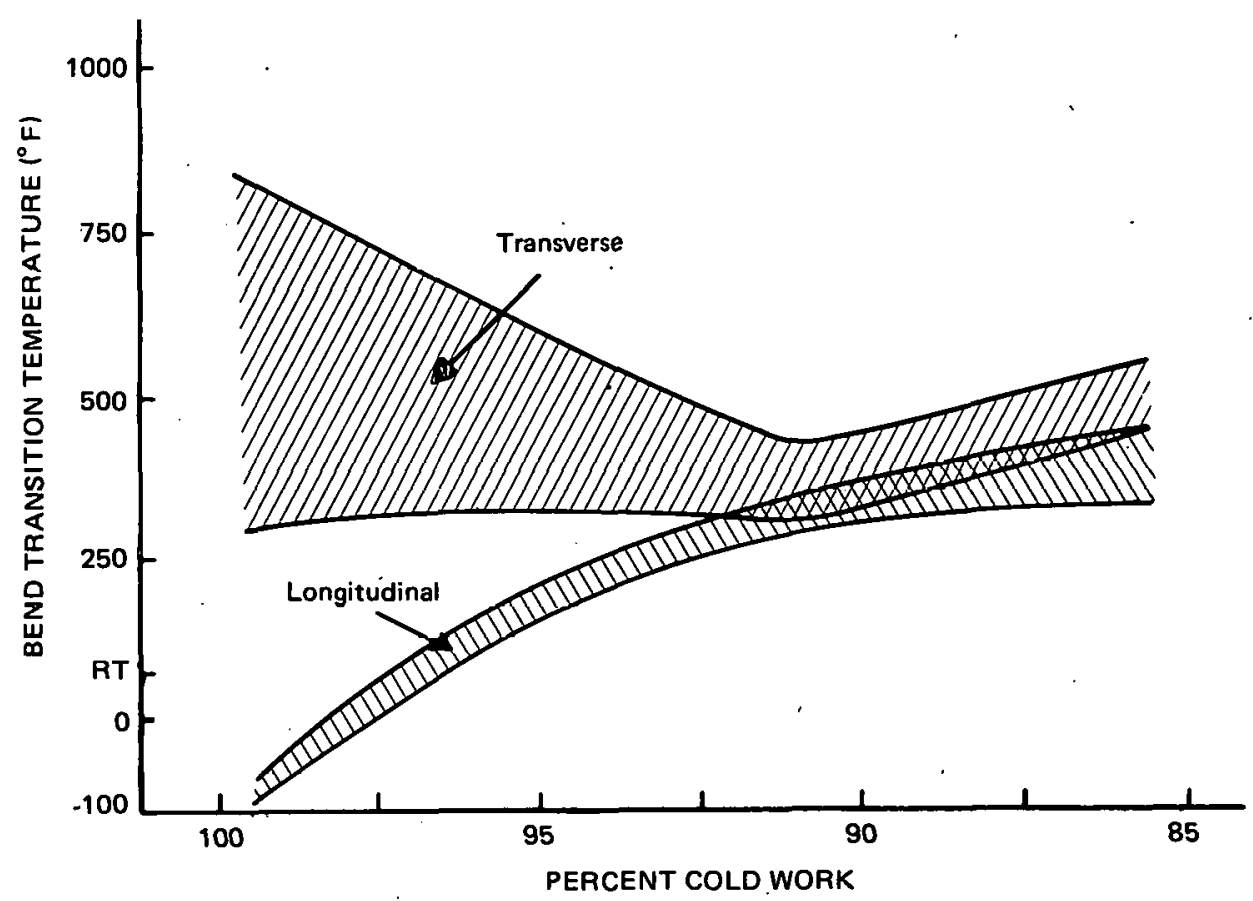

FIGURE 1. Bend Transition Temperature Versus Percent Cold Work (Fusco)

direction decreases only to the $92 \%$ cold working level (Fusco, Hegedus). These effects are depicted in Figure 1.

Another authority comments that the DBTT decreased with increased retained cold work (Maykuth). Schmidt and Bartlett, however, state that since tungsten is used frequently at temperatures higher than the recrystallization temperature, retained cold work is not an attractive mode for improving low-temperature behavior (Schmidt).

\section{Grain Boundaries}

Tungsten is known traditionally for its grainboundary weaknesses and the limiting effect of these boundaries on the ductility of the metal (Leber). Tungsten has a very low solubility of interstitial elements; consequently, any excess above the solid solubility agglomerates in the grain boundaries (Barr). However, the development of high-angle grain boundaries imparts the ductility of tungsten more than the normal content of interstitial elements. Both the segregation of impurities or interstitial elements at the boundaries and the grain boundary itself impair the ductility of tungsten more than the normal content of interstitial elements (Wilkinson-1969).

\section{Grain Size}

As the grain size of tungsten-sintered material is reduced, the total grain-boundary surface area is increased, and the possible concentration of grainboundary impurities is decreased (Schmidt). The ultimate result is an increase in ductility of tungsten as the grain size is reduced, as evidenced by the lowering of the DBTT (Leber). Mash and his coworkers believe that the void volume of wrought material should be maximized to disperse and segregate the impurities. This would prevent any continuous linkage of impurities and would reduce chances for embrittlement. A cold-worked fibrous microstructure has a lower DBTT than an equiaxed grain structure. The reason is that longer grain boundaries prevent formation of continuous precipitates of carbon, nitrogen, oxygen, and hydrogen along the grain boundary (Mash). There 
is more boundary length than precipitate available to form a continuous precipitate.

Molybdenum additions to tungsten have the desirable effect of reducing grain width. A maximum contribution is realized at $4 \%$. An alloy containing $4 \%$ molybdenum plus 20 - to $60-\mathrm{ppm}$ carbon has a grain width of $0.6 \mathrm{~mm}$. (Grain width approximates grain size.) Tungsten metal with 20to $60-\mathrm{ppm}$ carbon and $0 \%$ molybdenum has a grain width of $2.0 \mathrm{~mm}$ (Barr).

Carbon additions to arc-cast tungsten are performed to react with oxygen impurities and release $\mathrm{CO}$ under vacuum while forming the material. An addition of 300-ppm carbon maximizes the grain-wid th reduction to $0.9 \mathrm{~mm}$, compared to a $2.0-\mathrm{mm}$ grain width with a $10-$ ppm carbon addition (Barr).

Sintered powder-metallurgy tungsten that has been warm-worked to $75 \%$ reduction has 50 to 100 grains per square millimeter. These grains will recrystallize by vacuum annealing for one hour at $2000^{\circ} \mathrm{C}$, but will remain small (100 to 50 grains per square millimeter). Subjecting tungsten with $5 \%$ warmwork to the same temperature produces large grains ( 4 to 2 grains per square millimeter). For tungsten that is warm-worked $30 \%$, the $2000^{\circ} \mathrm{C}$ anneal produces 25 to 20 grains per square millimeter (Wilkinson-1970).

\section{Annealing or Stress Relieving}

Stress-relieving has been proposed as a method for improving the ductility of tungsten sheet. Optimum forming characteristics for tungsten sheet come after giving the sheet a stress-relief at 1095 to $1150^{\circ} \mathrm{C}$ (depending upon sheet thickness). This relief provides 1 to 5\% recrystallization. It also lessens the anisotropy and therefore enhances forming. Stress-relieved tungsten sheet may be more ductile at room temperature than "as-received" sheet (Fusco, Hegedus).

Recrystallization generally produces a material with a higher DBTT; therefore, recrystallization is avoided in most manufacturing processes (Maykuth, Pattee-1974, Crimmins, Syre). Yet, high-temperature annealing (2000 to $\left.2600^{\circ} \mathrm{C}\right)$ under high vacuum conditions gives a transition temperature of $100^{\circ} \mathrm{C}$ in the bend test (Syre).

\section{Heat Treating}

Webster and Eyre propose a method of increasing the workability of fully recrystallized tungsten. This technique involves heating tungsten to the recrystallization temperature in a gaseous hydrocarbon atmosphere and then cooling, preferably at a rate of $250^{\circ} \mathrm{C} / \mathrm{min}$, to prevent grain growth (Wcbster).

\section{Recrystallization}

Recrystallized tungsten in excess of 5\% is generally considered detrimental to the fabricability and integrity of tunsten sheet (at room temperature) (Fusco, Hegedus). Recrystallized tungsten of 250 grains per square millimeter has a DBTT of $750^{\circ} \mathrm{F}$; recrystallized tungsten of 600 grains per square millimeter has a DBTT of $650^{\circ} \mathrm{F}$. This can be compared to tungsten fabricated without recrystallization, which has a $400^{\circ} \mathrm{F}$ DBTT (Schmidt). One mode of recrystallization is that random dislocations move to boundaries, and these dislocation pileups at the grain boundaries can produce subsequent embrittlement. The DBTT is then raised since cleavage fractures may nucleate from these distinct grain boundaries (Wilkinson-1969).

At' elevated temperatures, the statements about ductility of recrystallized versus unrecrystallized tungsten reverses. Maykuth presents data showing tungsten sheet in the recrystallized condition with a higher ductility at elevated temperatures than unrecrystallized material. These data are presented in Table 2 (Maykuth).

Inhibition of secondary recrystallization can result from dilute alloy additions of rhenium, which benefit low-temperature ductility. Recrystallization is a time-dependent mechanism; therefore, short exposure to temperature can allow working in the plastic range without recrystallization (Wilkinson1969). 
TABLE 2. Average Tensile Properties of Fansteel Tungsten Sheet* (Maykuth)

\begin{tabular}{|c|c|c|c|c|c|c|c|}
\hline \multirow[b]{2}{*}{$\begin{array}{l}\text { Gage } \\
\text { (in.) }\end{array}$} & \multirow[b]{2}{*}{$\begin{array}{c}\text { Test } \\
\text { Temperature } \\
\left({ }^{\circ} \mathrm{F}\right)\end{array}$} & \multicolumn{3}{|c|}{ Optimum Condition } & \multicolumn{3}{|c|}{ Recrystallized Condition** } \\
\hline & & $\begin{array}{l}\text { Ultimate } \\
\text { Tensile } \\
\text { Strength } \\
\text { (ksi) }\end{array}$ & $\begin{array}{c}\text { Yield } \\
\text { Strength } \\
\text { (ksi) }\end{array}$ & $\begin{array}{l}\text { Elongation } \\
\text { In One Inch } \\
(\%)\end{array}$ & $\begin{array}{l}\text { Ultimate } \\
\text { Tensile . } \\
\text { Strength } \\
\text { (ksi) }\end{array}$ & $\begin{array}{l}\text { Yield } \\
\text { Strength } \\
\text { (ksi) }\end{array}$ & $\begin{array}{c}\text { Elongation } \\
\text { In One Inch } \\
\quad(\%)\end{array}$ \\
\hline \multirow[t]{6}{*}{0.060} & 75 & 200. & 195 & 0.7 & 56 & - & 0 \\
\hline & 1200 & 85 & 77 & 7 & 47 & 11 & 53 \\
\hline & 2000 & 64 & 61 & 8 & 37 & 11 & 39 \\
\hline & 2500 & 56 & 48 & 10 & 27 & 8.0 & 52 \\
\hline & 3000 & 18.0 & 7.1 & 64 & 19.0 & 8.3 & 58 \\
\hline & 3500 & 12.0 & 6.1 & 54 & 11.5 & 6.0 & 49 \\
\hline \multirow[t]{5}{*}{0.100} & 75 & 198 & 193 & 0.6 & $>65$ & - & 0 \\
\hline & 2000 & 68 & 63 & 11 & - & - & - \\
\hline & 2500 & 54.5 & 44 & 12 & 30 & 7.8 & 52 \\
\hline & 3000 & 17.2 & 7.4 & 77 & 18.3 & 6.2 & 56 \\
\hline & 3500 & 12.4 & 5.6 & 70 & - & - & - \\
\hline
\end{tabular}

*Average of at least duplicate tests on longitudinal samples.

**Held one hour at $2550^{\circ} \mathrm{F}$.

\section{Ductile-Brittle Transition Temperatures}

Face-centered-cubic metals exhibit little change in yield strength or ductility down to low temperatures. Body-centered-cubic metals such as tungsten, however, exhibit a large increase in yield strength (or a simultaneous decrease in ductility) over a narrow temperature range (Bechtold). This sharp change in mechanical properties is the ductilebrittle transition temperature (DBTT). The ductile-brittle transition can be understood by the mechanism of propagating the crack. A brittle fracture elongates itself with very little plastic deformation of the metal adjacent to the crack. A ductile fracture elongates itself as a result of intense localized plastic deformation of the metal at the tip of the crack.

The DBTT of tungsten is controlled and determined by the following physical properties, mechanical techniques of preparation, and physical conditions of evaluation:

1. The content of impurities and especially those impurities concentrated at interstitial sites (refer to the sections entitled "Additives" and "Impurities" for specific examples)
2. All factors that govern the entire fabrication process, such as working temperature, degree of reduction, and placement of stress-relief operation

3. Physical properties, conditions, and dimensions of the final product, such as the final state (whether stress-relieved or recrystallized), thickness, structure, grain size, and surface condition

4. The nature of the experimental stress applied (tensile, bending, impact) in addition to test parameters (speed of testing) and preparation of the specimens (notched or unnotched) (Syre).

The transition temperature range for pure tungsten is 150 to $450{ }^{\circ} \mathrm{C}$ (Pattee-1974). This temperature increases with an increase in strain rate. The tensile transition of tungsten, for example, may be approximately $200^{\circ} \mathrm{C}$, but with rapid strain rates as formed with the Charpy V-notch test, ductile behavior may not appear until $1000^{\circ} \mathrm{C}$ (Hargrave).

The DBTT, as represented by bend-test data, is presented for varying thicknesses of tungsten sheet. These data are reproduced in Table 3 (Maykuth). 
TABLE 3. Bend Transition Temperatures for Unrecrystallized Tungsten Sheet (Maykuth)

\begin{tabular}{|c|c|c|c|c|}
\hline \multirow{2}{*}{$\begin{array}{c}\text { Sheet } \\
\text { Thickness } \\
\text { (mil) } \\
\end{array}$} & \multirow[b]{2}{*}{ Direction } & \multirow{2}{*}{$\begin{array}{c}\text { Number } \\
\text { of Sheets } \\
\text { Tessted } \\
\end{array}$} & \multicolumn{2}{|c|}{$\begin{array}{c}\text { Bend Transition } \\
\text { Temperature }\left(^{\circ} \mathrm{F}\right)\end{array}$} \\
\hline & & & Ranges & Average \\
\hline 10 & $\begin{array}{l}\text { Longitudinal } \\
\text { Transverse }\end{array}$ & $\begin{array}{l}10 \\
10\end{array}$ & $\begin{array}{l}10 \text { to } 210 \\
14 \text { to } 215\end{array}$ & $\begin{array}{r}91 \\
108\end{array}$ \\
\hline 20 & $\begin{array}{l}\text { Longitudinal } \\
\text { Transverse }\end{array}$ & $\begin{array}{r}6 \\
10\end{array}$ & $\begin{array}{l}150 \text { to } 430 \\
200 \text { to } 495\end{array}$ & $\begin{array}{l}268 \\
355\end{array}$ \\
\hline 60 & $\begin{array}{l}\text { Longitudinal } \\
\text { Transverse }\end{array}$ & $\begin{array}{l}8 \\
9\end{array}$ & $\begin{array}{l}300 \text { to } 570 \\
360 \text { to } 770\end{array}$ & $\begin{array}{l}430 \\
503\end{array}$ \\
\hline 100 & $\begin{array}{l}\text { Longitudinal } \\
\text { Tranovoroo }\end{array}$ & $\stackrel{5}{5}$ & $\begin{array}{l}370 \text { to } 640 \\
460 \text { to } 725\end{array}$ & $\begin{array}{l}474 \\
560\end{array}$ \\
\hline
\end{tabular}

TABLE 4. Physical Properties of Tungsten and Molybdenum (Hargrave)

*A five-times-thickness (5T) punch radius was used for all material except the 10 -mil sheet, for which a 6T-purch radius was used.

\begin{tabular}{|c|c|}
\hline & Molybdenum \\
\hline Melting Point $\left({ }^{\circ} \mathrm{C}\right)$ & 2620 \\
\hline Density $\left(\mathrm{g} / \mathrm{cm}^{3}\right)$ & 10.22 \\
\hline Linear coefficient of expansion (per ${ }^{\circ} \mathrm{C}$ ) & $5.35 \times 10^{-6}\left(0-20^{\circ} \mathrm{C}\right)$ \\
\hline Specific heat (cal/g) & $0.058\left(25^{\circ} \mathrm{C}\right)$ \\
\hline Thermal conductivity (c.g.s. ${ }^{*}$ ) & $0.346\left(17^{\circ} \mathrm{C}\right)$ \\
\hline Vapor pressure (mm Hg) & $\begin{array}{l}5 \times 10^{-4}\left(2200^{\circ} \mathrm{C}\right) \\
1 \times 10^{-2}\left(2400^{\circ} \mathrm{C}\right)\end{array}$ \\
\hline Young's modulus ( $\left(\mathrm{b} / \mathrm{in} .^{2}\right)$ & $47 \times 10^{6}$ \\
\hline
\end{tabular}

$\frac{\text { Tungsten }}{3410}$
19.3
$4.43 \times 10^{-6}\left(20^{\circ} \mathrm{C}\right)$
$0.033\left(20^{\circ} \mathrm{C}\right)$
$0.31\left(20^{\circ} \mathrm{C}\right)$
$4 \times 10^{-8}\left(2200^{\circ} \mathrm{C}\right)$
$4 \times 10^{-6}\left(2400^{\circ} \mathrm{C}\right)$
$.50 \times 10^{6}$

\section{TUNGSTEN PHYSICAL PROPERTIES}

\section{Physical Properties}

Table 4 shows relevant physical properties of tungsten that are applicable to satisfying thermal operating conditions in addition to withstanding the chemical environment. The physical properties of molybdenum are also given to serve as a reference for the tungsten and to show similarities between the two elements. 
TABLE 5. Impurity Levels (in ppm) of Commercial Tungsten (Syre)

\begin{tabular}{|c|c|c|c|}
\hline Impurities & $\begin{array}{c}\text { Powder } \\
\text { Metallurgy } \\
\end{array}$ & $\begin{array}{c}\text { Electro-Arc } \\
\text { Melted }\end{array}$ & $\begin{array}{c}\text { Electron } \\
\text { Beam Melted }\end{array}$ \\
\hline Oxygen & $5-50$ & $5-20$ & $5-20$ \\
\hline Nitrogen & $5-50$ & $1-10$ & $1-10$ \\
\hline Hydrogen & $0-2$ & $0-2$ & $0-2$ \\
\hline Carbon & $5-200$ & $5-30$ & $5-20$ \\
\hline Iron & $10-100$ & $10-50$ & $10-20$ \\
\hline Nickel & $5-50$ & $1-5$ & $1-5$ \\
\hline Molybdenum & $20-100$ & $10-50$ & - \\
\hline Silicon & $5-50$ & $5-30$ & $2-10$ \\
\hline Aluminum & $5-40$ & $1-10$ & $1-10$ \\
\hline Chromium & 510 & & - \\
\hline
\end{tabular}

Thermal conductivity influences the cycling rate of a system containing a tungsten crucible. The thermal conductivity for tungsten decreases with increasing temperature. Within the range of 100 to $1000^{\circ} \mathrm{F}$, the conductivity decreases from 1225 to $800 \mathrm{Btu} \mathrm{hr}^{-1} \mathrm{ft}^{-2}{ }^{\circ} \mathrm{F}^{-1}$ in. ${ }^{-1}$. From 1000 to $3000^{\circ} \mathrm{F}$, this value decreases gradually to 710

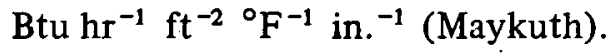

The thermal expansion coefficient represents an important parameter since a tungsten, corrosionresistant liner must expand over the temperature-cycling range at a rate similar to that of the shell (possibly carbon) in which it is contained. Otherwise, resultant stresses caused by an expansion mismatch might result in the forming of fissures and subsequent failure.

The coefficient of thermal expansion of tungsten remains reasonably constant from $2.4 \times 10^{-6}$ to $2.5 \times 10^{-6}$ (in./in.) $/{ }^{\circ} \mathrm{F}$ from 100 to $2500^{\circ} \mathrm{F}$ (Maykuth).

Any containment or transfer device fabricated from tungsten would have to be used in a protective atmosphere; otherwise it would oxidize at an elevated temperature. Tungsten and molybdenum oxidize readily when heated in air, and the oxides formed at temperatures above $500^{\circ} \mathrm{C}$ are nonprotective. In fact, molybdenum trioxide is volatile at temperatures above $700{ }^{\circ} \mathrm{C}$, and the rate of oxidation at higher temperatures is quite rapid--the metal almost literally "going up in smoke." Although the volatility of the oxides of tungsten is.not significant until higher temperatures are involved, tungsten's oxidation rate approaches that of molybdenum and is far in excess of accepted high-temperature materials. Consequently, heating unprotected metals for prolonged periods in oxidizing atmospheres must be avoided (Hargrave, Pattee-1974).

\section{Chemistry}

The impurities contained in fabricated tungsten products are influenced by both the preparation of tungsten powder and the process of fabrication, which may introduce impurities into the final tungsten part. An example of this latter case is the contamination of electrowon tungsten sheet by molybdenum, which originates from the molybdenum sheath used to enclose tungsten during rolling (Keith). Table 5 shows the impurity contents of commercial tungsten products.

Dopants frequently are added during the preparation of tungsten powder, mainly to improve certain physical properties for wire. Dopes consist principally of alkaline silicates (the greater part evaporates during sintering) or compounds of aluminum, sodium, potassium, or silicon oxide. The use of dope increases the recrystallization temperature and may bring it up to more than $2000^{\circ} \mathrm{C}$ (Syre).

\section{TUNGSTEN FABRICATION}

\section{Sintered Crucible}

Argonne National Laboratory has used pressed and sintered tungsten crucibles measuring $254 \mathrm{~mm}$ (10 in.) i.d. by $305 \mathrm{~mm}$ (12 in.) o.d. by $508 \mathrm{~mm}$ (20 in.) high. These crucibles were fabricated by isostatic pressing against a mandrel at approximately $2.0 \times 10^{9}$ dynes per square centimeter $(30,000 \mathrm{psi})$ 
and were sintered in an inert atmosphere for $12 \mathrm{hr}$ at $2200{ }^{\circ} \mathrm{C}$. A theoretical density of $92 \%$ is adequate for containing molten salt and metal without seepage.

The overall performance of pressed and sintered tungsten crucibles has been good, but the required thick walls make the crucibles heavy and difficult to handle remotely.

The only crucible failure was attributed to trying to remelt metal and salts that had solidified in the crucible. The thermal expansion variance of the metal and salt during heat-up cracked the crucible. 'The maximum size crucible made for Argonne by Union Carbide has been $356 \mathrm{~mm}$ (14 in.) i.d. by $654 \mathrm{~mm}$ (25.75 in.) high by $19.8 \mathrm{~mm}$ (0.78 in.) wall (Winsch).

\section{Rolling}

Personnel at Fansteel Inc. found the best all-around density of sintered tungsten and the maximum density of rolled tungsten sheet came with the following processing conditions:

1. Undoped powder with an average particle size of 3.65 to 3.9 microns

2. Isostatically pressed into 1 - by 6 - by 13 -in. bars under 35,000-psi pressure

3. Sintered for $1 \mathrm{hr}$ at $1700^{\circ} \mathrm{C}$ followed by $9 \mathrm{hr}$ at $2300{ }^{\circ} \mathrm{C}$

4. Rolled at 1150 to $1450^{\circ} \mathrm{C}$ to avoid recrystallization during rolling

Workability of sheet was determined through formability tests, room-temperature and elevatedtemperature tensile tests, and DBTT values (Maykuth).

Breakdown rolling of a $25.4-\mathrm{mm}$ ( 1 in.)-thick sintered billet at 1350 to $1450^{\circ} \mathrm{C}$ produces a better surface and more uniform microstructures than does rolling at $1590^{\circ} \mathrm{C}$. Intermediate and final rolling should be done at the lowest practical temperatures, usually about 1150 to $1040{ }^{\circ} \mathrm{C}$. Tungsten thinner than $1 \mathrm{~mm}(0.040 \mathrm{in}$.) is rolled at 200 to $300^{\circ} \mathrm{C}$. The bend transition tempera- ture is decreased through cross-rolling and by in-process stress-relieving for short periods at $1150^{\circ} \mathrm{C}$.

Tungsten foil can be produced as thin as 2.5 microns ( 0.0001 in.) through pack-rolling at room temperature. The procedure is to start pack-rolling at 12.7-microns ( 0.0006 in.) thickness, taking a reduction of 10 to $15 \%$ per pass until a total reduction of $50 \%$ is reached. At this point, stressrelieve $30 \mathrm{~min}$ at $950^{\circ} \mathrm{C}$. Continue rolling the new pack but rotate the rolling direction $90^{\circ}$ to the previous direction (Wilkinson-1970).

\section{Forging}

Arç-càst ingots of tungsten ordinarily are unforgeable because of brittleness from as-cast columnar grains.

Forgeability of conventional pressed and sintered tungsten decreases rapidly with increased diameters: Forgeable billets from powder metallurgy larger than $7.5 \mathrm{~cm}$ ( $3 \mathrm{in}$.) in diameter are extremely difficult to produce.

Forging, if done carefully, is possible on sintered tungsten bars while they are cooling from 1800 to $1050^{\circ} \mathrm{C}$ (Wilkinson-1970).

\section{Extrusion}

Solid billets of tungsten can be extruded into bars or rods with relative ease. Extruding hollow rounds or sleeves of tungsten into good quality tubes has been more difficult. Cladding the billet aids extrusion of the tube. The best cladding material is niobium but this is expensive; molybdenum makes a good substitute. Molybdenum, being more ductile than tungsten, lessens the extrusion force required. Yet, molybdenum is stiff enough for the filler to constrain the tungsten tube (Wilkinson-1970).

An arc-cast ingot requires less force to extrude than sintered tungsten. Sintered tungsten extrudes with $\mathrm{K}=360$ to $180 \mathrm{~kg} / \mathrm{mm}^{2}$ (510,000 to $\left.180,000 \mathrm{psi}\right)$ at 1600 to $1960^{\circ} \mathrm{C}$. For arc-cast tungsten, the corresponding $\mathrm{K}$ values are 130 to $100 \mathrm{~kg} / \mathrm{mm}^{2}$ $(183,000$ to $140,000 \mathrm{psi})$, and for electron beam 
melted tungsten, $\mathrm{K}=146$ to $120 \mathrm{~kg} / \mathrm{mm}^{2}(208,000$ to $173,000 \mathrm{psi}$ ) (Wilkinson-1970).

Tungsten has been extruded at 1200 to $2100{ }^{\circ} \mathrm{C}$ without lubricant, with glass or copper lubricant, or cladded with niobium or molybdenum sheaths (Wilkinson-1970).

Techniques for extruding tungsten and tungstenalloy tubing from arc-cast and powder-metallurgically prepared billets by the floating-mandrel method were developed at Oak Ridge. Natural forming tungsten oxide served as the lubricant. Extrusion temperatures ranged between 1650 and $2250^{\circ} \mathrm{C}$, and extrusion ratios ranged between 4 and 9 . Satisfactory service was obtained from zirconia-protected dies and mandrels, but surface melting of the container sleeve began when billet temperatures exceeded $1850^{\circ} \mathrm{C}$. Rapid extrusion speeds were necessary to minimize heat loss and reduce contact time with the tooling (Nelson).

\section{Forming}

Maykuth worked to form a dimple in tungsten sheet 0.010 and 0.020 in. thick. He used 0.125-, $0.156-$, and 0.188 -in. ( $1 / 8,5 / 32$, and $3 / 16$ in.) diameter balls. He concluded dimpling could not be recommended for use on tungsten sheet using conventional equipment and practical forming temperatures (Maykuth).

Dimpling only stretches the metal; drawing minimizes stretch and basically forms the metal with little change in thickness. Because of this difference, Maykuth's work on forming was successful in drawing 2-in.-diameter, 1-in.-deep cups from both the 0.60 - and 0.100 -in.-thick tungsten. The punch was heated to $340^{\circ} \mathrm{C}$, the die to $595^{\circ} \mathrm{C}$. The temperature at draw for the 0.100 -in.-thick material varied from 870 to $1010^{\circ} \mathrm{C}$ and from 680 to $815^{\circ} \mathrm{C}$ for the 0.060 -in.-thick tungsten (Maykuth).

Fusco conducted a study on the effect of stressrelieving on tungsten versus formability. After stress-relieving above $1650^{\circ} \mathrm{F}$ (notably $2100^{\circ} \mathrm{F}$ ), both a dimple and an evaporation boat could be formed, without defect. This could not be done with tungsten that was stress-relieved at $1650^{\circ} \mathrm{F}$ or below (Fusco).
TABLE 6. Minimum Shearing Temperature for Tungsten (Maykuth)

\begin{tabular}{|c|c|c|c|}
\hline \multirow{2}{*}{$\begin{array}{l}\text { Gage } \\
(\mathrm{mm})\end{array}$} & \multirow{2}{*}{$\begin{array}{l}\text { Thickness } \\
\text { (in.) }\end{array}$} & \multicolumn{2}{|c|}{$\begin{array}{l}\text { Minimum Shearing } \\
\text { Temperature }\left({ }^{\circ} \mathrm{C}\right)\end{array}$} \\
\hline & & Square & Rotary \\
\hline 025 & 0.010 & 150 & 180 \\
\hline 0.51 & 0.020 & 220 & 270 \\
\hline 1.52 & 0.060 & 480 & 515 \\
\hline 2.54 & 0.100 & 650 & 675 \\
\hline
\end{tabular}

Proper preparation of the edges of blanks is necessary in forming molybdenum or tungsten. All edges in tension during forming must be rounded or polished to prevent fracture propagation. Shearing and sawing cause edge-cracking and delamination, which must be removed before forming (Metals Handbook).

Union Carbide Corporation's Y-12 plant at Oak Ridge, Tennessee drawns an 8.1-in.-dia by 0.40 -in. blank of tungsten into a 4.75-in.-i.d. hemishell using the following forming parameters:

Draw ring die clearance $20 \%$

Draw ring material Reonite

Punch and draw ring temperature $\quad \sim 350^{\circ} \mathrm{C}$

Blank temperature $1010^{\circ} \mathrm{C}$

Lubrication:

Blank - two coats of Reonite 25 (graphite
plus mica)

Punch and draw ring - Fiskes 605D

The specifics of this drawing procedure include

1. Draw speed of approximately $6 \mathrm{in} . / \mathrm{min}$.

2. Blank holder pressure of 4 tons.

3. Multistep draw to minimize temperature loss of the blank to the tooling. (Each of the three steps in the draw are followed by reheating in a furnace.)

4. Propane torches heat the tooling and maintain heat in the tungsten during the drawing operation (Smith).

Hot-square and rotary-shearing studies were conducted on four gages of tungsten sheet. The minimum preheating temperatures required are shown in Table 6 (Maykuth). The recommended 


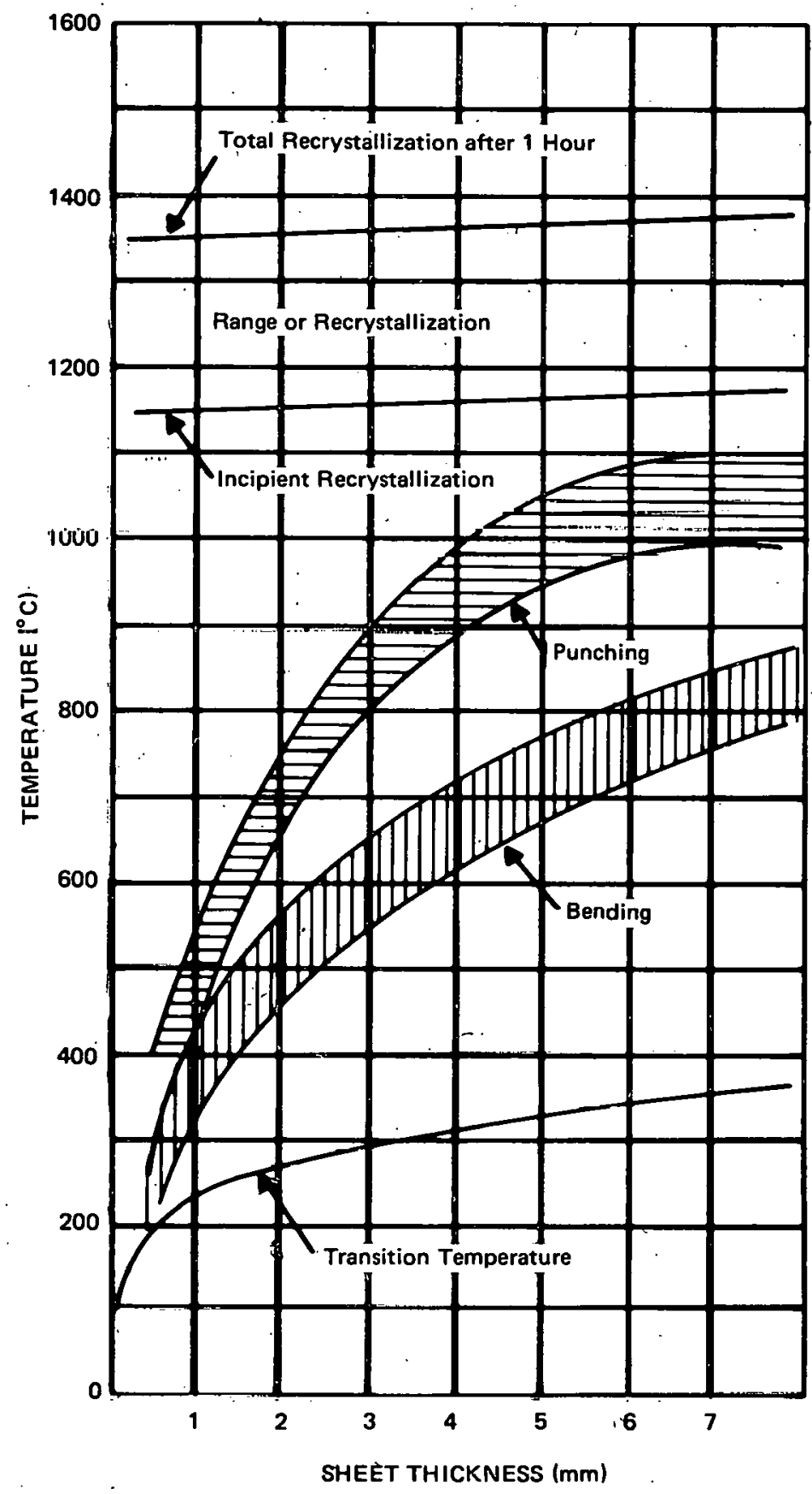

FIGURE 2. Working Temperature for Tungsten Sheet (Metallwerk Plansee)

working temperature for sheet tungsten is graphically presented in Figure 2.

The concept of fabricating rocket nozzles by inserting tungsten sheet into graphite has been considered. Large sheetmetal liners may offer a problem in longitudinal buckling along the axis. The cause would be the lack of a thermal expansion match between the graphite and tungsten sheet. It is hoped that this problem can be overcome through cushions, such as graphite cloth bonded with phenolic resins, that will absorb the expansion. Also, the use 
of interposed layers with intermediate expansion characteristics offers another possibility ( $\mathrm{Jaffee}$ ).

\section{Spinning Tungsten}

Capability

Crucibles, especially of tungsten, find application in nuclear fuel recycling processes. Fabrication depends on size and wall thickness--small crucibles are vapor-deposited; large ones are spun.

Large crucibles range from 5 to $24 \mathrm{in}$. in diameter and 15 to 48 in. in length. Wall thicknesses are 0.125 in. Form-, shear-, and extrusion-spinning techniques are employed in their fabrication. Formspinning to a cylindrical shape is by multiple preforming of large-diameter, thin-sheet blanks; shear-spinning uses heavy-wall, small-diameter spin blanks. Spinning temperatures for preforming range from 1260 to $1315^{\circ} \mathrm{C}$ in shear-spinning and 980 to $1090^{\circ} \mathrm{C}$ in thin-wall form-spinning.

Crucibles with a length-to-diameter ratio greater than $2: 1$ require extrusion-spinning after formspinning. End-trimming of the cylinders and machine-conditioning of the outside surface are performed prior to extrusion-spinning. Removal of up to 0.030 in. of stock eliminates fish scaling and circumferential folds. Forward extrusionspinning to the required length is done in consecutive passes at 950 to $1150^{\circ} \mathrm{C}$, depending on the part's wall thickness. Mandrel speed is $200 \mathrm{rpm}$ and the feed rate is $2 \mathrm{ipm}$. Set-up of the machine for extrusion-spinning involves close control over machine deflection, templăte taper versus mandrel taper alignment, and mandrel run-out. It also resembles the set-up for shearspinning. Extrusion-spun crucibles generally have a surface finish of $50 \mathrm{rms}$ or better in the as-spun condition (Mash).

The largest tungsten crucible technically convenient to make by shear-spinning rolled tungsten sheet is about $1 \mathrm{ft}$ in diameter by $1.5 \mathrm{ft}$ high (Wilkinson1970).

Japka and Hoppin believe that the maximum size on shear-spun formed parts is limited only by the size of available tungsten plate, which in 1962, and still true today, is $24 \mathrm{in}$. square and $0.5 \mathrm{in}$. thick (Japka).

\section{Material Requirements}

Japka found no difference in spinnability of doped 218 -grade tungsten and pure tungsten. All of Japka's work was on 0.100 -in.-thick tungsten sheet (Japka).

For optimum spinning results with tungsten, starting material should be uniform, have a relatively fine grain (ASTM 5 to 9), and be warm-worked 50 to $70 \%$. The sheet or plate should be stress-relieved after manufacture; however, no recrystallization should occur during this operation. The surface finish of the starting preforms should approximate $64 \mathrm{rms}$ and should contain no surface nicks, laps, or seams that would act as stress risers during or following spinning (Crimmins).

All of the tungsten sheet formed in initial experiments was in the as-rolled condition. Since work-hardening of this material had not been a serious problem, initial process development did not include annealing or recrystallization of the sheet or intermediate conical shapes produced before forming the final nozzle shape. However, some edge delaminations were found in the nozzle shapes formed. Those delaminations suggested severe working had caused the formation of incipient laminations that opened upon trimming. It was found that by starting with recrystallized tungsten sheet, there was less chance of forming delaminations in parts during further processing than by starting with as-rolled sheet. Additionally, it was evident that the fully recrystallized sheet was easier to shear-spin and caused less machine deflection (Japka).

Tensile strength data gathered by Japka support the statement that recrystallized sheet is easier to spin. In Table 7, note the increased elongation for the recrystallized sheet versus unrecrystallized sheet at comparative temperatures. Another point is that within the broad working range of 1400 to $2000^{\circ} \mathrm{F}$, the tensile properties do not change appreciably. Thus, considerable variation in the 
TABLE 7. Tensile Data on Doped and Undoped 0.100-in.-Thick Tungsten Sheet* (Japka).

\begin{tabular}{|c|c|c|c|c|}
\hline \multirow[t]{2}{*}{ Condition } & $\begin{array}{c}\text { Testing } \\
\text { Temperature } \\
\left(^{\circ} \mathrm{F}\right)\end{array}$ & $\begin{array}{l}\text { Ultimate Strength } \\
\text { (psi) }\end{array}$ & $\begin{array}{l}0.2 \% \text { Yield Strength } \\
\text { (psi) }\end{array}$ & \multirow[t]{2}{*}{$\begin{array}{c}\text { Elongation in } \\
\text { One-Inch } \\
\text { Gage Length }\end{array}$} \\
\hline & & Undo & d Sheet & \\
\hline As-Rolled & 1400 & 53,300 & 52,700 & 10.0 \\
\hline Parallel to Grain & $\begin{array}{l}1700 \\
2000\end{array}$ & $\begin{array}{l}49,500 \\
45,300\end{array}$ & $\begin{array}{l}48,900 \\
44,400\end{array}$ & $\begin{array}{l}11.0 \\
12.0\end{array}$ \\
\hline Recrystallized** & $\begin{array}{l}1400 \\
1700 \\
2000\end{array}$ & $\begin{array}{l}36,100 \\
30,800 \\
26,100\end{array}$ & $\begin{array}{r}15,500 \\
15,300 \\
14,500\end{array}$ & $\begin{array}{l}48.0 \\
43.0 \\
44.5\end{array}$ \\
\hline & & Dol & Sheet & \\
\hline As Rolled & 1400 & 69,300 & 39,400 & 15.7 \\
\hline Parallel to Grain & 1700 & 57,900 & 55,000 & 15.7 \\
\hline Recrystallized ${ }^{* *}$ & $\begin{array}{l}1400 \\
17 @ 0 \\
2000\end{array}$ & $\begin{array}{l}34,900 \\
31,550 \\
27,200\end{array}$ & $\begin{array}{l}15,020 \\
15,620 \\
14,650\end{array}$ & $\begin{array}{l}50.8 \\
51.5 \\
45.8\end{array}$ \\
\hline
\end{tabular}

shear-forming temperature is allowed without danger of fracture. The data demonstrate that in this temperature range, tungsten sheet is very ductile. The ductility of tungsten, as measured by elongation, can be deceiving, however, because elongation in the as-rolled sheet specimen was localized near the fracture area while the recrystallized specimen elongated uniformly.

In Super Temp Corporation's evaluation of spinning 0.250 -in.-thick tungsten blanks, they saw differences in grain size of the blanks but no difference in spinnability. The plate from Metallwerk Plansee exhibited a much coarser fibrous grain structure (approximately ASTM 6.5) (Bauer).

Shear-spinning of pressed and sintered tungsten cylinders of 92 to $95 \%$ density, but with no prior warm work, was unsuccessful (Crimmins).

\section{Spinning Parameters}

Six 0.250 -in.-thick by 12 -in.-diameter tungsten plates, two from each supplier--Metallwerk Plansee,
General Electric, and RMSP--were successfully spun into cylinders $5 \frac{3}{8}$, in. in-diameter by approximately 6 in. deep. This was accomplished using three spinning operations while heating the blanks to $1950^{\circ} \mathrm{F}\left(1066^{\circ} \mathrm{C}\right)$. The mandrel (H21 tool steel) was heated to $800^{\circ} \mathrm{F}$ and the rollers to $400^{\circ} \mathrm{F}$. The contact radius on the rollers was $3 / 8$ in. Blank preparation included one hour of stress relieving at $2100^{\circ} \mathrm{F}\left(1150^{\circ} \mathrm{C}\right)$ prior to spinning and then stress-relieving immediately following the shear-spinning operation for $2 \mathrm{~min}$ at $2000^{\circ} \mathrm{F}$. The spinning speed was $200 \mathrm{rpm}$; the feed rate was 2 ipm (Bauer).

A typical, conventional, spinning operation for tungsten is performed at 815 to $1045^{\circ} \mathrm{C}$. Torch heat is applied to a tungsten sheet blank while it is spun with an external roller to the contour of the rotating mandrel (Wilkinson-1970).

Austrian tungsten, which was sintered at a higher temperature than was customary in 1961 for American tungsten $\left(2500\right.$ versus $2200^{\circ} \mathrm{C}$ ), had better spinning characteristics; but neither source had adequate reproducibility (Wilkinson-1970). 
Powder-metallurgy sheet formed and welded into cylinders, $146 \mathrm{~mm}$ ( $5.75 \mathrm{in}$.) in diameter with a $25-\mathrm{mm}$ ( 0.10 in.) wall thickness can be shear-spun in three passes at 890 to $920^{\circ} \mathrm{C}$, producing a cylinder of $7.5-\mathrm{mm}$ ( $0.03 \mathrm{in}$.) wall thickness (Wilkinson-1970).

The cylinders obtained by form-spinning 0.060-in.thick sheet were used in forward extrusion-spinning studies using a hydraulic power spin lathe. Six sheet parts, each $5 \%$ in. in inside diameter, were cut to 5 -in. lengths and stress-relieved $1 \mathrm{hr}$ at $1040{ }^{\circ} \mathrm{C}$. For these parts, optimum extrusion-spinning was accomplished in two passes with the material at $900{ }^{\circ} \mathrm{C}$, using a mandrel speed of $200 \mathrm{rpm}$ and a feed rate of $2 \mathrm{ipm}$. Three cylinders spun from $0.250-$ in.-thick plates also were evaluated. Each of these was $5 \%$ in. in inside diameter, cut to a $4 \frac{3}{4}$-in. length, and stress-relieved $1 \mathrm{hr}$ at $1095^{\circ} \mathrm{C}$. To maintain a good surface, it was necessary to first remove 0.02 to $0.03 \mathrm{in}$. of metal from the surface of the 0.250 -in.-thick, form-spun cylinders. For the plate material, optimum extrusion-spinning was accomplished using the same parameters as for the sheet material, except the spinning temperatures were higher. Thus, for the plate, the first pass was performed at $1065^{\circ} \mathrm{C}$ and the second pass at $1010^{\circ} \mathrm{C}$ (Maykuth).

Shear-forming (spinning) 11 -in.-diameter by 0.240 in.-thick unrecrystallized blanks into $60^{\circ}$ cones was completely successful. A $1 / 8$-in.-radius work roll was used along with working temperatures of $1095^{\circ} \mathrm{C}$.

The $60^{\circ}$ cones were next shear-formed into $30^{\circ}$ cones using the following shear-forming conditions: a $1 / 8$-in. roll radius, a roll feed setting of $2 \mathrm{ipm}$, and a working temperature of $980^{\circ} \mathrm{C}$. All $60^{\circ}$ cones were successfully formed into $30^{\circ}$ cones with a 0.060 -in. wall thickness.

The work just described, using 0.240 -in.-thick tungsten, was repeated but with tungsten discs 0.5 -in. thick. The only difference here, in the Inachine set-up, was that a 0.25 -in. radius roll was now used to accommodate the 0.5-in.-thick material.

The 0.5 -in. tungsten plate, as-received, was in the moderately rolled condition, probably with about
$50 \%$ warm work. It had occasional areas of partial recrystallization, though it was not deliberately recrystallized after rolling. Experimentation with shear-forming these plates at $1095^{\circ} \mathrm{C}$ indicated that hairline cracks formed on the inside surface after the part was finished. Eventually discovered was the necessity of shear-forming the 0.5 -in. plate into $60^{\circ}$ cones at a minimum temperature of $1200^{\circ} \mathrm{C}$. When this was done, the series of operations in shear-forming from a flat plate to a $60^{\circ}$ cone and then to a $30^{\circ}$ cone could be completed successfully. One conclusion was that the thicker the material, the higher the shear-forming temperature needed (Japka).

Tungsten and molybdenum are always given a stress relief immediately after spinning. Mash recommends $3 \mathrm{~min}$ at $1065^{\circ} \mathrm{C}$ for tungsten and $3 \mathrm{~min}$ at $870{ }^{\circ} \mathrm{C}$ for molybdenum. In each case, the metal is slow cooled after the treatment (Mash).

In shear-spinning tungsten, thickness reduction in excess of $50 \%$ in one pass is not recommended. To shear-spin a $60^{\circ}$ cone from a 10 -in.-diameter by 0.250 -in.-thick blank, the mandrel is heated to approximately $500^{\circ} \mathrm{C}$ and the part to between 980 and $1150^{\circ} \mathrm{C}$. Heating is accomplished with oxyacetyline torches. Care must be exercised to prevent heating the part above $1150^{\circ} \mathrm{C}$ since recrystallization may occur. For this spinning operation, the mandrel speed is $250 \mathrm{rpm}$, the feed rate is $6 \mathrm{ipm}$, and the contact radius $0.5 \mathrm{in}$. (Crimmins).

$\underline{\text { Evaluation }}$

Argonne National Laboratory found that the spun tungsten crucible is adequate in all respects for the pyrochemical processing of spent nuclear fuels. However, technology limits the crucible size to $280 \mathrm{~mm}$ (11 in.) o.d. by $457 \mathrm{~mm}$ (18 in.) high (Winsch).

\section{Spinning--General Practice}

\section{General Information}

Spinning is an efficient and economical method of producing cones, hemispheres, cylinders, and other radially symmetrical, hollow parts in a wide variety of sizes and contours. Parts ranging from 0.25 in. 
$(6.4 \mathrm{~mm})$ to $20 \mathrm{ft}(7.9 \mathrm{~m})$ in diameter have been spun from metals up to $3 \mathrm{in}$. ( $76 \mathrm{~mm}$ ) thick (Wick).

A major advantage to spinning is low cost, particularly for prototypes. Also, spinning can consistently produce close tolerances. In spinning cylinders, close dimensional control is achieved by using at least two passes (Wick, Boulger).

\section{Equipment}

In 1966, both NTW Missile Engineering Incorporated and Ladish Company owned equipment capable of shear-forming cylinders $10 \mathrm{ft}$ in diameter and more than $15 \mathrm{ft}$ long (Boulger).

Spinning machines are made and sold by Autospin, Inc., Carson, California; Flotum, Inc., Cincinnati, Ohio; and L\&F Industries, Huntington Park, California. Floturn sells the equipment developed by Lodge and Shipley Company; L\&F Industries now makes the Hydrospin machines originally developed by Cincinnati Milacron (Wick).

\section{Spinning Lubricants}

Because of localized forming forces, the requirements for lubricants are somewhat more stringent than for other types of forming. Common lubricants used at elevated temperatures on titanium and certain nickel-base alloys are solid film types such as graphite, molybdenum disulfide, and mica (Boulger).

\section{Troubleshooting}

Cracks through the wall usually are caused by heavy-wall reductions or when using a tool having a radius that is too sharp.

Laminations in spinning are similar to "fish-mouth," a defect observed during cold-rolling sheet when using small reductions. The solution to preventing laminations usually lies in continually taking reductions larger than $10 \%$ (Boulger). $\underline{\text { Metal Characteristics }}$

Any metal that can be formed can be spun. The main microstructural requirement of this metal is fine grain size. For steel, an ASTM of 4 or finer grain size provides the best surface finish after spinning (Boulger).

Heating Methods

Torches may be the crudest method of heating metal for spinning, but they are the most effective because the flame does not interfere with spinning rollers (Boulger).

\section{Ring Rolling}

The first known success with ring-rolling tungsten was reported by Reisner Forge Company in 1961. Rings 11 in. in diameter with 0.75 -in. wall thickness have been rolled from pressed and sintered preforms (Jaffee).

\section{Explosive Forming}

Fxplosive forming of tungsten has the advantage of forming the part without oxidation. Medzyanovskiy explosively formed spheroidal cups $50 \mathrm{~mm}$ in diameter and $18 \mathrm{~mm}$ deep from a $60-\mathrm{mm}$ diameter by $1.6-\mathrm{mm}$-thick blank. The procedure was to first coat the blank with a pyrotechnic composition. This blank was placed over a die and covered with sand. Igniting the pyrotechnic composition brought the blank to a temperature range of 940 to $1000^{\circ} \mathrm{C}$ in 25 seconds. At this point, the explosive in the sand was ignited forcing the blank into the die (Medzyanovskiy).

Explosive forming at elevated temperatures has been accomplished successfully in several American laboratories. Liquid metals, salt baths, sand, alumina, and air have been used as the hot transfer media.

Tungsten has been formed at 800 to $900^{\circ} \mathrm{C}$.

Frequently the tungsten is sandwiched between stainless steel to reduce heat loss. Although successful in the laboratory, industry has not gone to hot explosive forming because of the complexity and 


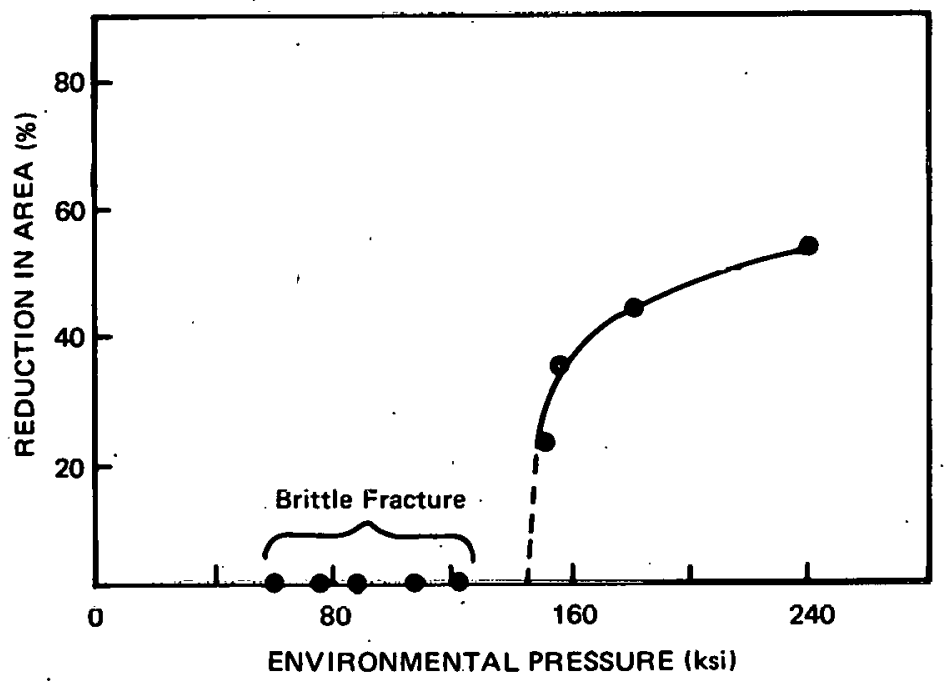

FIGURE 3. Dependence of Ductility on Environmental Pressure for Tungsten Rod - Tensile Test (Stack)

cost of the operation and the hazards associated with using explosives in hot temperature media (Haegland).

\section{Exotic Forming}

Tungsten can be formed at room temperature if hydraulic pressure is applied. The minimum pressure required is $160 \mathrm{ksi}$ (Figure 3). Applications include extrusion, wire drawing, closed die forgings, and bending (Stack).

\section{Slip Casting}

Tungsten can be slip-cast into a crucible shape. Los Alamos Scientific Laboratory slip-casts 1.5-in.diameter by 0.75 -in.-high crucibles. Larger sizes would be difficult because the product shrinks 18 to $20 \%$ upon sintering and is likely to crack (Stoder).

\section{Machining}

Heating tungsten above the DBTT is a prerequisite for most machining operations on tungsten unless sub-zero machining is used.
The two major problems in conventional machining of tungsten is short tool life and chipping of the tungsten. Using tungsten carbide cutting tools with positive rake increases tool life. In turning, cuts deeper than 0.060 in. create cutting forces that tend to break the tool; cuts less than 0.015-in. deep produce excessive wear. To prevent chipping the tungsten, terminate all cuts before the tool reaches unsupported surfaces.

Since 1965, the Central Shops Department of Argonne National Laboratory has been testing and applying sub-zero coolants while turning and drilling tungsten. Results have sometimes been favorable when conventional methods were futile.

The coolant, 25 vol \% trichloroethylene in a kerosene-like solvent (Stoddard Solvent) plus 6.3 cubic centimeter of alcohol per litre of coolant to prevent freezing, is cooled to $-40^{\circ} \mathrm{C}$ to accomplish the sub-zero machining.

Chasing threads on tungsten was once considered impossible. The only successful method of threading tungsten was by grinding. However, the sub-zero coolant technique now makes possible the chasing of threads on pure, high-density tungsten with a single-point tool. A 1.5-in.-long ( $3 / 4 \mathrm{UNC}$ ) finished thread can be accurately chased in $45 \mathrm{~min}$. 
TABLE 8. Tooling Recommendations for Turning Tungsten and Molybdenum (Hargrave)

\begin{tabular}{|c|c|c|}
\hline & Tungsten & Molybdenum \\
\hline Tool Material & $\begin{array}{l}\text { Hard metal (Prolite'1C grade for } \\
\text { general turning, threading, } \\
\text { and drilling. Prolite } 15 \mathrm{~A} \text { for } \\
\text { work involving intermittent } \\
\text { cutting) }\end{array}$ & High speed steel \\
\hline Cutting Speed & $30-50 \mathrm{fpm}$ & $30-50 \mathrm{fpm}$ \\
\hline Feed & $0.003-0.006 \mathrm{in} . / \mathrm{rev}$ & About $0.003 \mathrm{in} . / \mathrm{rev}$ \\
\hline Depth of Cut & $0.01-0.015 \mathrm{in}$ & $0.015-0.060$ in. \\
\hline \multicolumn{3}{|l|}{ Tool Point Angles } \\
\hline Approach Angle & $5-45^{\circ}$ (depending on operation) & $30^{\circ}$ \\
\hline Back Radii & 0 & $10^{\circ}$ \\
\hline Trail Angle & $3-5^{\circ}$ & $45^{\circ}$ \\
\hline Side Radli & $5-10^{\circ}$ & $5^{\circ}$ \\
\hline Side Clearance & $3^{\circ}$ & $5^{\circ}$ \\
\hline Nose Radius & Very small & $0.020-0.030 \mathrm{in}$ \\
\hline
\end{tabular}

\begin{abstract}
Abrasive cut-off of tungsten bars is normally done with wheel speeds of 5500 to $6500 \mathrm{fpm}$ using a copious flow of soluble oil coolant and a cutting rate of one square inch in three to five min. For sections up to 4 in. in diameter, a 16-in. diameter, $1 / 16$-in.-thick carbide wheel (Grade C-120-KRA) works well (Wilkinson-1970).
\end{abstract}

Hargrave comments that tungsten and molybdenum are only slightly more difficult to machine than high-strength super alloys based on nickel and cobalt. He recommends heating the workpiece to the range of 200 to $300{ }^{\circ} \mathrm{C}$; this considerably improves the machinability. To maintain this heat, cutting fluids are not used. Hargrave's tooling recommendations for turning tungsten and molybdenum are given in Table 8 (Hargrave).

Because tungsten will not maintain a small radii, threads must be truncated (Hargrave).

In drilling tungsten, use tungsten carbide-tipped drills and avoid breakthrough to ensure a clean hole. Drill from both sides of the workpiece to avoid breakthrough (Hargrave).
Grinding of tungsten should be carried out with a soft wheel, such as a Universal $80 \mathrm{M}$, so there is approximately even removal of wheel and workpiece. More-than-usual care should be taken to avoid overheating. This can be accomplished by flooding the job with coolant. Harder wheels are used for finishing off intricate parts, but great attention must be paid to avoid crazing (Hargrave).

The final shaping of tungsten parts frequently is done by grinding. Silicon carbide wheels in hardness $J$ to $L$ and a grain size of $100-120$, and aluminum oxide wheels with hardness $H$ to $K$ and a grain size of $40-80$ have proved useful for most. applications. During grinding, maintain adequate cooling with an oil emulsion (Metallwerk Plansee).

\section{Tube Manufacturing}

Transfer Tube

Argonne National Laboratory developed a method for transferring molten zinc and halide salts at $800^{\circ} \mathrm{C}$. The tubing material selected was 


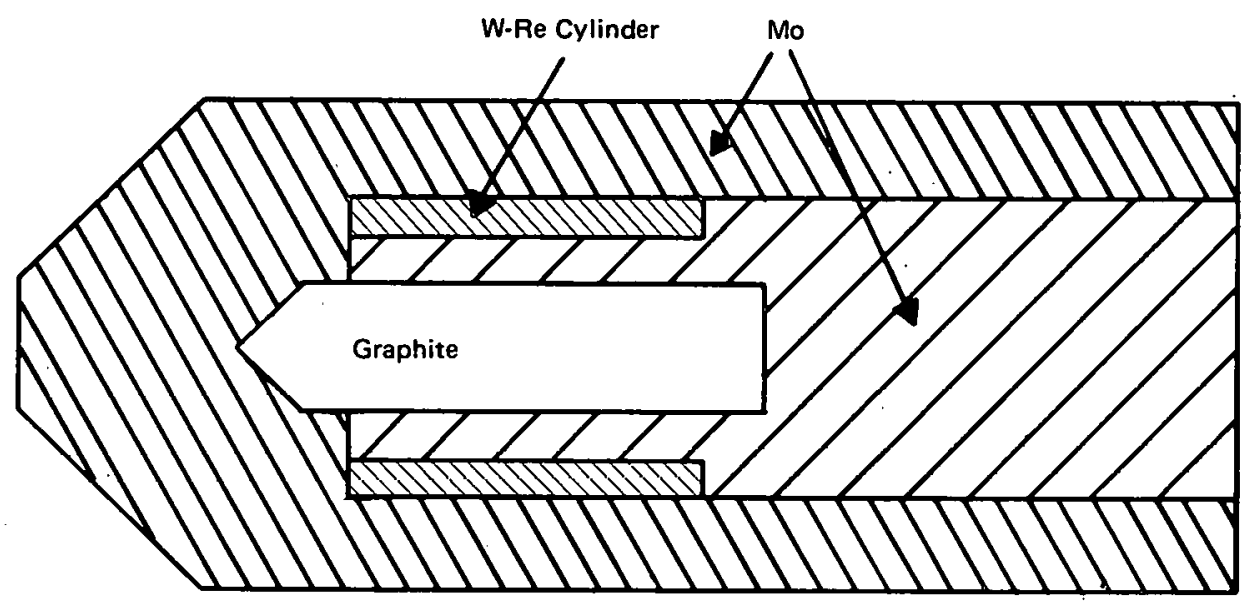

FIGURE 4. Filled-Extrusion Billet for Extruding Tungsten - 25\% Rhenium Tube

molybdenum $-30 \%$ tungsten. This material, like tungsten, is corrosion resistant to the molten salt and metal; however, molybdenum - $30 \%$ tungsten is more machinable and formable than tungsten and is available in longer lengths (up to $10 \mathrm{ft}$ can be gun-drilled).

Bending of the tube was accomplished by heating to $1400^{\circ} \mathrm{C}$ with oxyacetylene torches set with a reducing flame to minimize oxidation of the tube's outer surface. Argon purging of the inside of the tube prevented oxidation. Tools for bending were made from molybdenum $-30 \%$ tungsten.

Connections were made by machining threads on the tube and coupler. The thread used was a modified Whitworth shape with 16 threads to the inch. The modifications included rounded roots to reduce the chance for breakage. Machining these threads requires a sharp tool with a 25 to $27^{\circ}$ positive rake. To ensure a complete seal, a 0.010 -in.-thick tantalum gasket was placed between the butt ends of the tube, and the coupling was brazed to the tube using a palladium-nickel braze alloy.

To prevent solidification during transfer of the metals and salts, the tube was heated (by stranded Chromel heater wire wrapped around the tubing) to a temperature slightly higher than the $800{ }^{\circ} \mathrm{C}$ (Grosvenor).

\section{Tube Fabrication}

A tube-drawing program was initiated in 1964 to draw tungsten and tungsten-rhenium tube for a nuclear application project. Nuclear Metals Division of Textron, Inc., developed the "filled billet" technique for tube extrusion. (See Figure 4.)

Through a series of moving mandrel draws, Textron was able to draw $64 \mathrm{ft}$ of tungsten $-25 \%$ rhenium tubing having a 0.250 -in. o.d. by 0.020 -in.-thick wall.

The "filled billet" technique requires that the filler material extrude like tungsten. Molybdenum satisfied this requirement. The billet for the tungsten $-25 \%$ rhenium extrusion is welded within an enclosed chamber of inert gas that remains through the extrusion. The extrusion temperature is $1600^{\circ} \mathrm{C}$.

Drawing with a solid, stationary mandrel (M2 or M3 steel for tungsten $-25 \%$ rhenium) provides two advantages. (See Figure 5.) First, it permits etching out the molybdenum core after extrusion when the diameter-to-length ratio is still large. This permits faster etching. Secondly, the solid mandrel smoothes the extrusion lines on the inside of the tube (Isserow).

Drawing of tungsten $-25 \%$ rhenium was accomplished on the as-extruded tube. This drawing involved a $10 \%$ reduction per draw. Fifty percent 


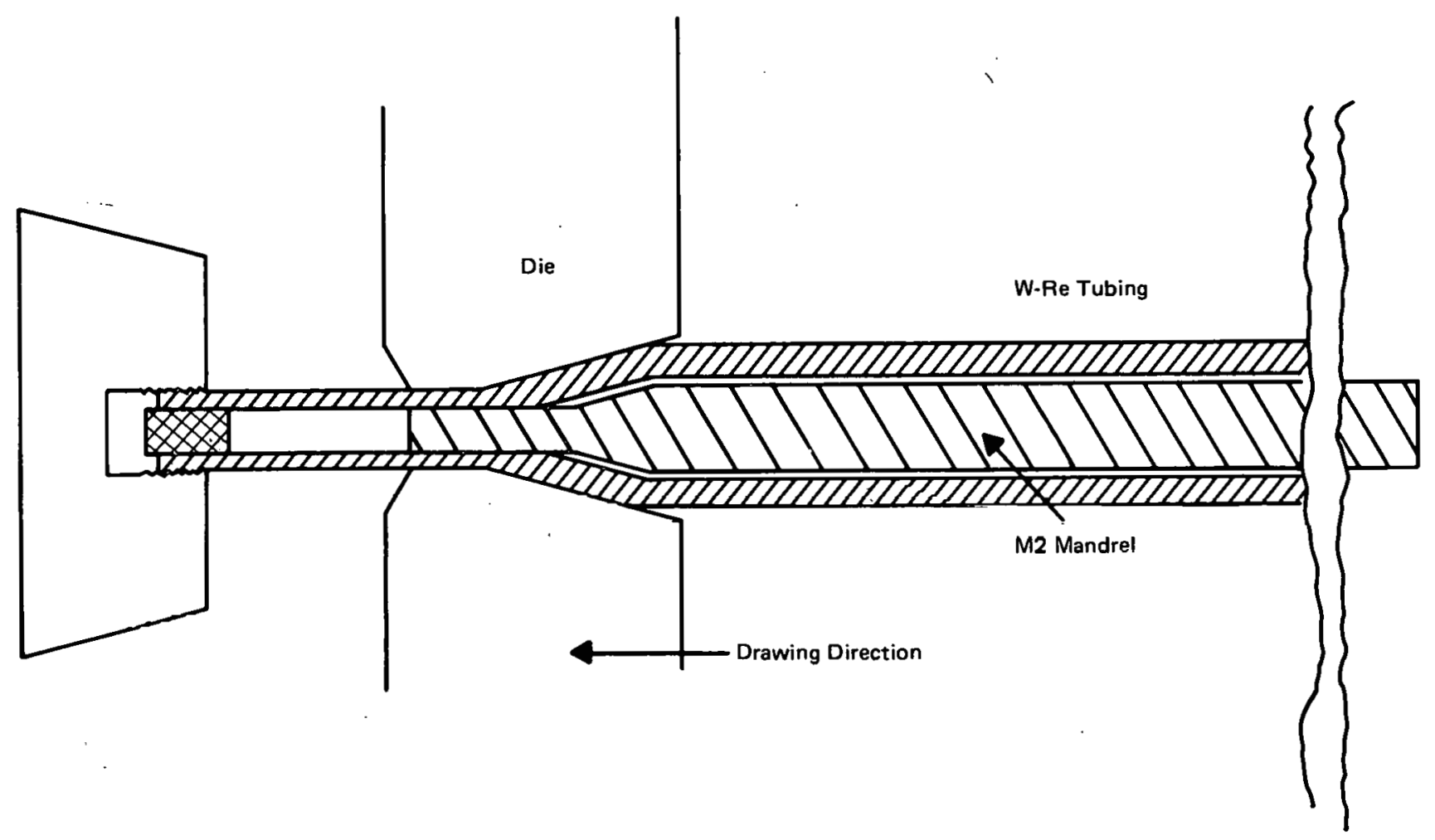

FIGURE 5. Technique for Drawing Tube With Stationary Mandrel (Isserow)

total reduction could be made before requiring a one-hour anneal at $1400{ }^{\circ} \mathrm{C}$.

Mayfield and Burt continued the report on the tubedrawing effort at Textron. They state that efforts to draw pure tungsten were dropped in favor of tungsten $-25 \%$ rhenium because of the crack propagation characteristics in tungsten (Mayfield).

Improvements in the Textron extrusion process include the GE-NMPO technique of using a small hafnium-center core rod in the molybdenum filler. This decreases etching time to remove the molybdenum core after extrusion. However, hafnium is expensive. The Minnesota Mining and Manufacturing Company produces tube by extruding powder and sintering. This results in tubing with smooth surfaces but slightly lower density before the drawing operation.

Drawing of the tungsten $-25 \%$ rhenium tube is done either with a solid mandrel or a ductile core. With the ductile core method, the drawing temperature is 625 to $725^{\circ} \mathrm{C}$, and two passes of $10 \%$ reduction each are made before annealing at $1525^{\circ} \mathrm{C}$. For the solid mandrel method, the drawing temperature is reduced to $650^{\circ} \mathrm{C}$, but the frequency of anneals is the same (Mayfield).

Ductile, $100 \%$ molybdenum tubing can be formed by careful control of process variables and removal of contamination introduced during fabrication. Maximum ductility is obtained in the stress-relieved, fine-grained condition. Interstitial impurities in molybdenum, such as oxygen and carbon, must be left at a low level because they often segregate in the grain boundaries and decrease ductility. Processing of tube often concentrates the carbon and oxygen at the surface. This is removed by etching (Moorhead).

\section{PRODUCT AVAILABILITY}

\section{Tungsten Sheet}

Formable tungsten sheet is available in a thickness ranging from 0.001 to $0.500 \mathrm{in}$. Thicker plate lacks 
ductility because it lacks sufficient warm-working by rolling. All commercial tungsten comes from a sintered ingot, which requires 60 to $70 \%$ reduction by rolling before acceptable forming can be obtained.

Maximum width available commercially is 24 in. at 0.060 -in. or higher thickness. Metallwerk Plansee has a rolling mill that can roll sheet that is 40 in. wide, but they have no auxiliary equipment to handle this width (Bydash, Barto).

\section{Crucible Size}

Burk says his company (GTE Sylvania) has the capability to produce a sintered tungsten crucible as large as $24 \mathrm{in}$. in diameter and $48 \mathrm{in}$. high. This size crucible requires a minimum wall thickness of one inch to maintain the crucible's shape during the sintering process (Burk).

Seamless tungsten crucibles, through spinning by Metallwerk Plansee, are limited to 14 in. in diameter by 13 in. high (Bydash).

Metallwerk Plansee, in cooperation with Crucible Steel, made a 4.5 -ft-diameter by 14 -ft-high molybdenum crucible (Bydash).

\section{Tubing}

Tungsten Tubing

Tungsten tubing cannot be drawn but only machined. For Thermo Electron Corporation, the maximum length available is 6 in.; the maximum for Metallwerk Plansee is 12 in. (Bydash, Bernard).

Molybdenum - $30 \%$ Tungsten

Tubing with a 1 -in. i.d. can be gun-drilled to provide 10 -ft lengths (Bernard).

\section{Molybdenum Tubing}

Molybdenum tubing can be produced by conventional techniques such as extrusion and drawing, and is commercially available in sizes up to 1 -in. o.d. Larger sizes can be obtained, but they generally require gun-drilling from rod (Moorhead).

Drawn molybdenum tube measuring 1 -in. i.d. with a 0.030 -in.-thick wall is available in 20 -ft lengths (Bernard).

\section{JOINING OF TUNGSTEN}

\section{Overview}

This subject survey is confined to tungsten-joining technology. Its main emphasis is on brazing and fusion welding. Other topics discussed briefly are riveting, diffusion bonding, chemical vapor deposition (CVD) joining, and plasma spraying. There are three good survey works already available, which should be adequate background for many applications. These include, in addition to welding data, details on set-up and cleaning prior to joining (Pattee-1973, Wilkinson-1970, AWS).

\section{Background}

This survey has been compiled as part of an effort to produce crucibles for the non-aqueous reprocessing of nuclear fuel elements. The need for crucibles has been recognized for some time by Argonne National Laboratory. Reports of early work show that tungsten has excellent corrosion resistance when exposed to typical process materials at $800{ }^{\circ} \mathrm{C}$ (Bennett-1962). The main difficulty in obtaining tungsten crucibles for fuel reprocessing is the large size required. A large crucible could be fabricated from components by a joining process such as brazing, welding, riveting, diffusion bonding, CVD joining, or plasma spraying. Possible component shape would include rolled sheet or plate, and drawn or spun cups.

Table 9 lists some of the more important properties of tungsten, which need to be considered for fabrication. Tungsten's extremely high melting point and high-temperature strength make this element ideal in many aerospace applications, and its excellent corrosion resistance dictates its use for nuclear processing applications. On the negative side, however, are such adverse characteristics 
TABLE 9. Physical Properties of Tungsten (AWS)

\begin{tabular}{lcc}
\multicolumn{1}{c}{ Property } & \multicolumn{1}{c}{ Value } \\
Melting Point & & $3410^{\circ} \mathrm{C}$ \\
Density & & $19,000 \mathrm{~kg} / \mathrm{m}^{3}$ \\
$\begin{array}{l}\text { Ductile-to-Brittle } \\
\text { Transition Temperature (DBTT) }\end{array}$ & & $260-370^{\circ} \mathrm{C}$ \\
High-Temperature Strength & \\
Corrosion Resistance &
\end{tabular}

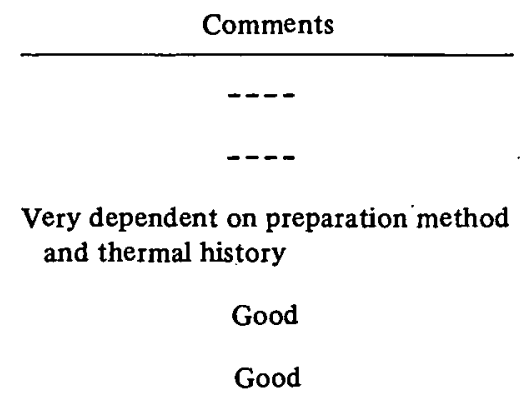

as high ductile-to-brittle transition temperature (DBTT) together with a pronounced susceptibility to embrittlement by recrystallization and to growth of large grains at elevated temperature. The result is that tungsten is difficult to fabricate by conventional processes. Welds typically are brittle (reminiscent of glass). Large temperature differentials can easily induce thermal cracking, especially when coupled with residual or restraint stresses; and mechanical forming, even at elevated temperatures (well above the DBTT), can result in the rapid transformation of one large piece of tungsten into many small pieces.

These physical properties dictate the forms of commercially available tungsten. The most common is sintered (and probably rolled) powder material. For many applications this is an ideal form because the sheets are easily formed and have some ductility, making mechanical fastening an attractive possibility. Large, complex shapes can be produced by pressing and sintering powder. One drawback with powderpressed tungsten is its susceptibility to forming weld porosity.

Another commercially available form is arc remelt material, which can be welded. with less porosity than powder sheet. However, it is more expensive than powder metallurgy sheet and is not readily available. Tungsten powder is available, and an increasingly popular fabrication method involves plasma spraying powder onto either a substrate (for use as a composite) or a mandrel (which is subsequently removed, most likely by etching). These products characteristically are quite porous, although porosity can be greatly reduced by sintering in a hydrogen environment. Other forms of tungsten sheet are (1) chemically vapor deposited (CVD) by the reduction of $\mathrm{WF}_{6}$ or $\mathrm{WCl}_{6}$ on a heated substrate, and (2) salt-bath plated by electrolytic deposition on a substrate in a molten alkali-metal fluoride bath. These last two forms are not as common as the preceding form of tungsten.

\section{Brazing}

Brazing is often used to join tungsten because agood joint can be formed without subjecting the tungsten to temperatures that could cause recrystallization. Brazing also voids the large grains and porosity of welding, which helps retain base-metal properties. Since tungsten forms oxides at relatively low temperatures $\left(500^{\circ} \mathrm{C}\right)$, brazing must be done in vacuum or in an inert environment. The choice of filler alloys is fairly critical because adverse metallurgical reactions can occur. An example of the compatibility problem is nickel-base braze alloys; a reaction can occur that results in tungsten recrystallization. Also, braze alloys with volatile components should be avoided for vacuum brazing (Pattee-1973).

For grouping purposes, brazing has been divided into three areas: (1) conventional brazing, (2) reactive brazing, and ( 3 ) braze welding. Reactive brazing implies that the braze alloy reacts with the tungsten to form intermetallics, and gives the brazement a higher remelt temperature than the 
TABLE 10. Brazing Alloys for Use With Tungsten (Robbins)

\begin{tabular}{ll}
$\begin{array}{c}\text { Alloy } \\
(\%)\end{array}$ \\
\hline $72 \mathrm{Ag}-28 \mathrm{Cu}$ \\
$58 \mathrm{Ag}-10 \mathrm{Pd}-\mathrm{bal} \mathrm{Cu}$
\end{tabular}

$65 \mathrm{~V}-35 \mathrm{Nb}$

\author{
Results \\ Adequate if tungsten is first plated with \\ silver-copper or nickel. \\ Probably $O K$ if tungsten is first plated. \\ with nickel. Further study \\ recommended. \\ Excellent. \\ Good wettability, but poor strength; \\ indicative of embrittlement. \\ Good wettability, but attached tungsten, \\ causing cracking. \\ Excellent wetting, but poor strength, \\ embrittlement.
}

*Not available commercially.

melting point of the original braze alloy. Braze welding is similar to fusion welding except that the filler-metal composition is different than that of the base metal.

\section{Conventional Brazing}

Haynes used tantalum and niobium foil for brazing tungsten (Haynes). The American Welding Society suggests using, in addition to tantalum and niobium, manganese and nickel-based brazing alloys (AWS). Pattee, however, points out a problem: nickel causes recrystallization in the tungsten (Pattee-1973). Young and Jones examined a large number of experimental braze alloys with several base alloys. They concluded that niobium $-2.2 \%$ boron is an excellent tungsten-braze alloy with good high-temperature strength at $1600^{\circ} \mathrm{C}$ (Young).

Robbins examined the suitability of a number of braze alloys (most of them available commercially) for brazing tungsten. His results are summarized in Table 10 (Robbins).

A series of patents have been granted on tungstenbrazing alloys for special purposes. Gilliland used a series of alloys from the vanadium-tantalumtitanium system for service temperatures of 925 to $1375^{\circ} \mathrm{C}$ (Gilliland-1966b). A British patent describes a binary braze alloy of tungsten with 35 to $45 \mathrm{wt} \%$ irridium that has a braze temperature of $2500^{\circ} \mathrm{C}$ (USAEC-1968). Replacing up to $10 \%$ of the tungsten with rhenium gives even stronger joints.

Marshall and Smith have patented alloys from the niobium-tantalum-vanadium system, including binary niobium-vanadium alloys. These alloys are brazed at temperatures between 1950 and $2500^{\circ} \mathrm{C}$ (Marshall-1967b). Marshall also holds a patent on alloys from the tungsten-ruthenium-rhenium system for brazing tungsten (Marshall-1968). These are meant to be brazed at 2300 to $2800{ }^{\circ} \mathrm{C}$ and include binary tungsten-ruthenium alloys. Another British patent claims that alloys from the molybdenumruthenium system give good results when brazing tungsten in the 1950 to $2500{ }^{\circ} \mathrm{C}$ range (USAEC1967).

An interesting application of brazing technology was presented by Bobrov, who mixed powdered braze alloys with tungsten and tungsten carbide 
powders during plasma spraying. The resultant sprayed product could then be sintered so the braze alloy would fill the voids in the tungsten. The braze alloys included copper and alloys such as silvercopper and copper-zinc for the tungsten carbides and nickel-manganese for tungsten (Bobrov).

\section{Reactive Brazing}

Reactive brazing is a fairly nonspecific process in that many, if not most, brazing alloys for tungsten cause some metallurgical reaction with the tungsten. It is implied that the metallurgical reactions involve those elements originally added to the alloy as melting-point depressants. Hence, the remelt temperature of the brazement is markedly higher than the original brazing temperature. A tungsten brazing alloy with this behavior is platinum $-3.5 \%$ boron, which forms tungsten boride in the base metal. Tungsten powder was also added to this braze to break up continuous tungsten boride stringers (Metcalfe).

A more complete reporting of this same type of work, including an iridium-boron series of alloys, is given by Haynes (Haynes). Additions of osmium, rhenium, ruthenium, titanium, and zirconium also. were made to the basic alloys, although these additions had little or no effect. A patent was granted on tungsten-brazing alloys from the molybdenum-rhenium-rhodium system (Marshall1976b). These alloys were found to have remelt temperatures higher than their original melting points, indicating that a reaction had taken place. Although the authors of the patent did not call this a reactive braze, it appears that this and many of the previously mentioned braze alloys, especially those in the patented ternary systems, would fit the description of reactive braze alloys.

\section{$\underline{\text { Braze Welding }}$}

The braze-welding joining process is simply fusion welding using a dissimilar filler metal. Gilliland used fillers of niobium, tantalum, molybdenum, rhenium, and a binary tungsten $-25 \%$ rhenium to join powder-metallurgy tungsten sheet. Although the niobium and molybdenum fillers gave the worst results, none of the braze welds were as good as fusion welds made during the same study (Gilliland-1966a). Cole reported similar work, using similar filler alloys. Not surprisingly, the results also were similar, leading to the conclusion that "use of a dissimilar filler metal (braze weld technique) did not improve the properties of the resulting joint but appeared to cause further embrittlement" (Cole).

St. Germain reports experimenting with resistance braze welding tungsten. Spot resistance welding tungsten procedures cracks because the tungsten cools rapidly and the combination of high temperature and pressure causes the welding electrodes to stick, and when separated, the tungsten cracks. To reduce the temperature requirement. he tried using thin foils $(0.002$ in.) of molybdenum and tantalum between the tungsten sheets; however, the molybdenum braze weld was extremely brittle, and the tantalum spot weld had some microcracking. St. Germain concluded that resistance braze welding is not suitable as a structural joining technique for tungsten (St. Germain).

\section{Welding}

Fusion welding of tungsten usually results in a brittle weldment because of the high DBTT of tungsten. The problem is compounded by the fusion process causing large grains in the fusion zone and recrystallization and grain growth in the heat-affected zone. The problem is made quite difficult by thermal stresses, both transient and residual, resulting from the localized heating characteristics of fusion welding processes. In many applications, however, fusion welding is capable of solving tungsten joining problems.

The largest amount of work seems to have gone into electron beam welding (EBW), mainly because the high heat input of EBW is a good solution to the problem of tungsten's high melting point. Bryant and Gold used EBW to join CVD tungsten coupons 0.060 -in. thick. The tungsten was produced by three processes: (1) deposition from $\mathrm{WF}_{6}$ (fluoride tungsten), (2) deposition from $\mathrm{WCl}_{6}$ (chloride tungsten), and (3) chloride tungsten deposited onto a substrate of 
fluoride tungsten (duplex tungsten). The only discernible difference between fluoride and chloride tungstens was that the chloride material had a large initial grain size. Results were obtained in the form of DBTT determined by longitudinal and transverse bend testing. These results verified that large grains cause a more brittle weldment, also that a grain orientation allowing only minimal stress accommodation of reorientation (e.g., along the centerline of the EB weld) also has low ductility (Bryant-1975b).

Lessman and Gold compared weldability of three tungsten alloys [pure tungsten, tungsten $-25 \%$ rhenium (by weight), and tungsten $-25 \%$ rhenium - 30\% molybdenum (atomic percent)] . Gas-tungsten arc welding (GTAW) and EBW both were used in the study. Lessman and Gold coupons were 0.035 -in. thick. Their results for unalloyed tungsten (arc-cast) indicate that the material is unweldable with either process, although EBW produced the most dramatic failures. These failures included delamination in the parent metal adjacent to the weld. The authors attributed the delamination to thermal shock. Thermal shock, caused by high rates of heat input, is measured in kilojoules per inch (Lessman).

Preheating to $760^{\circ} \mathrm{C}$ improved GTA weldability slightly. In the alloys, it was found generally that EBW produced welds that were as good as or better than GTAW. Arc-cast tungsten - 25\% rhenium was much more weldable with EBW, and was given an excellent rating. Arc-cast tungsten $-25 \%$ rhenium $-30 \%$ molybdenum was found unweldable by the GTAW process. Preheat was concluded to be necessary for EBW (and recommended for GTA welding) unalloyed tungsten. Postweld heat treatment generally was ineffective. Results from the alloy welds suggested that since thermal shock in GTAW is not as severe as in EBW, then postweld annealing is not as important as in EBW. Finally, welds in powder metallurgical materials always contained porosity whereas welds in arc-cast materials were porosity free (Lessman).

Gilliland examined several joining processes on several types of pure tungsten. He found that powder metallurgical tungsten could be welded by the GTAW process with a sizeable increase in
DBTT $-100{ }^{\circ} \mathrm{C}$ or more. However, in this experiment, if too high an annealing temperature were used (e.g., $2800^{\circ} \mathrm{C}$ ), extensive grain growth occurred and the DBTT was so high as to be unmeasurable. In addition, porosity was seen in the powder product welds. Electron-beam welds had DBTT values approximately $25^{\circ} \mathrm{C}$ lower than the GTAW welds. No postweld treatment was done on the EB welds (Gilliland-1966a).

Raab and Schock experienced similar results while electron-beam welding pure tungsten; i.e., the powder metallurgical material gave more porosity than did arc-cast, and preheating decreased cracking in the welds (Raab).

Nerodenko and co-workers examined the welding behavior of sintered (powder metallurgical) tungsten sheets approximately 0.080 -in. thick using GTAW and EBW processes. They found that preweld heating to $300{ }^{\circ} \mathrm{C}$ did not reduce the likelihood of cracks during welding. Cracks during welding seemed to increase with increasing travel speed for both processes. Postweld annealing was carried out for $2 \mathrm{hr}$ at 1200,1400 , and $1600^{\circ} \mathrm{C}$. All of these treatments increased mechanical properties of the welds, with the $1400^{\circ} \mathrm{C}$ anneal having the greatest effect. Annealing greatly affected the distribution of porosity in the welds. After a $1200^{\circ} \mathrm{C}$ anneal, the porosity was uniformly distributed in the weld metal. The $1400^{\circ} \mathrm{C}$ anneal left porosity mainly along the weld centerline, and the $1600^{\circ} \mathrm{C}$ anneal eliminated the porosity (Nerodenko).

Lundin and Farrell examined GTAW and EBW welds in 0.070-in. CVD tungsten sheet produced by fluoride reduction. The composition of this material was fairly typical of most high-purity tungsten except for the presence of about $20 \mathrm{ppm}$ (by weight) fluorine. Lundin and Farrell found that after annealing or welding, there was a considerable amount of microporosity that tended to nucleate along grain boundaries. Fractured specimens showed that failure occurred through almost continuous strings of pores, which were particularly dense along the edge of the fusion zone (Lundin). Another paper presents evidence that these pores do indeed link up to cause failure. The analysis includes CVD, powder metallurgy, and arc-cast tungsten, and attempts to correlate microporosity with microcracking (Farrell). 
Cole and his co-workers welded a series of materials, including pure tungsten (produced by several methods), and several tungsten alloys. All of the pure tungsten examined (commercial powder stock, GE-15, CVD, and arc-cast) required a preheat of at least $150^{\circ} \mathrm{C}$ for consistently acceptable welds. As expected, the powder-metallurgy tungstens showed gross porosity whereas the arc-cast material showed no porosity. Base-metal preparation did not, however, have a noticeable effect on DBTT; it was concluded that base-metal grain size was probably more significant than was the type of preparation. Postweld annealing substantially reduced the DBTT for all types of tungsten and all types of processes (EBW, GTAW, CVD joining, and braze welding). The main weldability advantages of the alloys come from their lower-than-room-temperature DBTT's. (The GE-15 is a proprietary powder metallurgical, unalloyed tungsten with low porosity. It is available from General Electric, Cleveland, Ohio.) (Cole)

\section{Other Joining Processes}

This section includes other joining methods that have been reported but do not fit into welding or brazing categories.

Plasma spraying is included as a joining topic because the process more or less resembles welding and because spraying could be used to protect welded or brazed joints. Argonne National Laboratory has reported spraying several materials, including tungsten, onto silicon carbide and 410 stainless steel (Bennett-1963, - 1964). The coatings were sprayed from $<12$-micron powder to a thickness of 0.030 to $0.035 \mathrm{in}$. The work was performed by Western Gear Corporation, Lynwood, California. Tungsten also was sprayed onto a tantalum substrate. These coupons were then subjected to 12 thermal cycles between 200 and $930^{\circ} \mathrm{C}$. The silicon carbide and tantalum substrate samples held up well, but the coating on the stainless steel substrate separated (Bennett- 1963, -1964). A later paper by Winsch summarizes results of these experiments. Thermal expansion was only one aspect of the problem, and it was found that as-sprayed tungsten was unacceptably porous. This porosity could be removed by sintering, a technique used in manufacturing free-standing tungsten crucibles by plasma spraying onto a mandrel (later removed by etching). However, sintering could not be applied to coatings sprayed on a silicon carbide substrate because the sintering temperatures $\left(1350^{\circ} \mathrm{C}\right)$ would destroy the silicon carbide (Winsch).

The Linde Division of Union Carbide has developed a process that densifies plasma-sprayed tungsten. This process involves impregnating the tungsten after plasma spraying with nickel nitrate and sintering at $1300^{\circ} \mathrm{C}$ in a hydrogen atmosphere (Taylor). The nickel is a sintering aid that eliminates porosity; however, the level of nickel concentration, less than one weight percent, is low enough to remove some of the corrosion concerns. With the nickel densification, it is possible to provide a free-standing plasma-sprayed tungsten crucible that does not leak.

Kitahara and Hasui examined the nature of bonding between plasma-sprayed coatings of nickel, chromium, molybdenum, tantalum, and tungsten; and substrates of aluminum and mild steel. Their metallurgical investigation showed the substrate surface is melted by the sprayed particles and that a boundary layer consisting of intermetallics is formed. This layer was found necessary for good adhesion between coating and substrate (Kitahara).

Diffusion bonding of tungsten has been reported by $D^{\prime}$ Annessa. He found that, in common with all diffusion bonding, proper surface preparation was critical. Surface conditioning could be achieved by hot or cold working to increase the dislocation (vacancy) density on the surface. Pressure applied during bonding would, in conjunction with the vacancies, promote diffusion. Adding a thin (0.001 in.) layer of dissimilar metal at the interface greatly enhanced diffusion. With tungsten, niobium was used at the interface with good results. However, nickel-interface material caused extensive substrate recrystallization and compound formation, as well as centerline voids resulting from interdiffusion. These results led the author to conclude that if joints are to last only a short while, then diffusion problems in bimetallic joints might be safely ignored. Producing joints that must last for sustained periods, however, requires judicious study of time-temperature-activity relationships 
for the proposed couples (D'Annessa). The problem of recrystallization of tungsten in the presence of nickel has also been observed in brazing (Pattee1973).

A U.S. patent exists that describes a method for diffusion-bonding tungsten and aluminum. Aluminum is bonded to tungsten by first clamping titanium foil to a tungsten body and holding this arrangement at $900{ }^{\circ} \mathrm{C}$ for one hour (in vacuum and inert atmosphere). An aluminum piece is then clamped to the titanium-tungsten assembly at the titanium side, with a load of 1000 psi. This entire assembly is then held in vacuum for one hour at $635^{\circ} \mathrm{C}$. Although the patent refers only to joining tungsten to aluminum and to titanium, it seems possible that tungsten could be bonded to itself by means of a titanium foil, intermediate layer (Hershenson).

Several different joining methods were reported by St. Germain. Among these were diffusion bonding [ with results similar to those of $D^{\prime}$ Annessa (1967)] and riveting.

Riveting was examined because of the embrittlement, recrystallization, and cracking associated with welding and brazing. Electro-discharge machining (EDM) was used to make 0.063 -in. diameter holes for riveting. The rivets were cut from 0.060 -in. swaged rod with allowance for heading. They were then heated to low red heat with an oxyacetylene torch and headed by impact (i.e., using a hammer and die block). Although there were hairline cracks in the rivet heads, these did not extend into the loadbearing bodies of the rivets. Microscopic defects around the electro-discharge machined holes caused substantial scatter in the data, but the results generally were good, leading the authors to conclude that riveting is a feasible way to join tungsten (St. Germain).

Gilliland reports using CVD as a joining method. An open-vee butt joint between powder-metallurgical tungsten sheets was filled in by CVD techniques. The results generally were good, although some cracking was observed. The author stated that the technique was being used successfully for tube closure welds (Gilliland-1966a). Cole et al., also examined CVD for joining. They found that narrow vee-joint preparations $\left(90^{\circ}\right.$ included angle) were prone to cracking, but that expanding the vee to a radius of $0.5 \mathrm{in}$. tangent to the weld root resulted in high-integrity joints. Subsequent stress relief at $1000{ }^{\circ} \mathrm{C}$ for one hour produced welded joints with a low $\left(200^{\circ} \mathrm{C}\right)$ DBTT (Cole). A good overview of CVD, as applied to tungsten joining problems, is given by Wilson. This reference includes a discussion of equipment required, joint preparation, and process parameters (Wilson).

\section{CHEMICAL VAPOR DEPOSITED TUNGSTEN}

\section{Information}

\section{Chemical Reactions}

Chemical vapor deposition (CVD) involves the absorption of mobile atoms on the substrate and their migration to form embryos, which on reaching critical size constitute stable nuclei. This growth occurs mainly by addition of monomers absorbed to kinks and ledges on the surface (Blocher).

Chemical vapor deposition tungsten can be produced by a variety of methods, which include hydrogen reduction of either the fluoride of tungsten $\left(\mathrm{WF}_{6}\right)$, the chloride of tungsten $\left(\mathrm{WCl}_{6}\right)$ or the carbonyl of tungsten $\left[\mathrm{W}(\mathrm{CO})_{6}\right]$.

Decomposition of any of these three compounds of tungsten will yield CVD tungsten. The following criteria govern the choice of reaction:

1. ease of use

2. starting material vaporization temperature

3. deposition temperature

4. product purity

5. starting material availability (McKnight)

Generally, tungsten is deposited by the hydrogen reduction of tungsten hexafluoride:

$$
\begin{aligned}
\mathrm{WF}_{6} \text { (gas) }+3 \mathrm{H}_{2} \text { (gas) } \frac{\text { heated }}{\text { substrate }} & \mathrm{W} \text { (solid) } \\
& +6 \mathrm{HF} \text { (gas) }
\end{aligned}
$$


Tungsten hexafluoride and hydrogen are premixed at a temperature high enough to prevent condensation. This vapor is then passed over a substrate that has been resistance or induction heated. The substrate temperature is sufficient to cause the desired chemical reaction. As the thicknesses-of the coating increases, the temperature of the body must be increased (McKnight).

Hydrogen reduction of $\mathrm{WF}_{6}$ has the advantage of forming a deposit as low as $400^{\circ} \mathrm{C}$ whereas the decomposition product requires a temperature of $1200{ }^{\circ} \mathrm{C}$ (McKnight).

Tungsten also can be deposited by reacting the tungsten halide with a metal vapor, which must also form a volatile metal halide. The following is an example.

$$
\begin{array}{r}
\mathrm{WF}_{6}+\text { metal (vapor) } \frac{\text { heated }}{\text { substrate }} \\
\mathrm{W}+
\end{array}
$$

(McKnight)

Tungsten coatings can be produced from WF at a rate of $0.001 \mathrm{ipm}$, with an efficiency as high as $90 \%$ or above. These gas-tight coatings are in excess of $99.7 \%$ of theoretical density, and thickness can be maintained with a close tolerance (McKnight).

Tungsten has a low susceptibility to reaction with molten metals and salts used in the separation of plutonium. Problems such as adhesion of the molten metal to the CVD tungsten coating must be solved or held to a minimum (Kyle-1972).

\section{Possible Side Reactions}

Impurities (as inclusions) can be generated in deposited tungsten, as represented by the following reaction:

$$
\begin{aligned}
& \mathrm{W} \text { (solid) }+4 \mathrm{HF} \text { (gas) } \rightarrow \mathrm{WF} \text { (solid) }+2 \mathrm{H}_{2} \text { (gas) } \\
& \text { then } 3 \mathrm{WF}_{4} \text { (solid) } \rightarrow \mathrm{W} \text { (solid) }+2 \mathrm{WF}_{6} \text { (sólid) }
\end{aligned}
$$

The solid tungsten hexafluoride is included in the coating. If water is present in the system, the following reactions can occur:

$$
\begin{gathered}
\mathrm{WF}_{4} \text { (solid) }+2 \mathrm{H}_{2} \mathrm{O} \text { (gas) } \rightarrow \\
\mathrm{WO}_{2} \text { (solid) }+4 \mathrm{HF} \text { (gas) } \\
\mathrm{WO}_{2} \text { (solid) }+2 \mathrm{HF} \text { (gas) } \rightarrow \\
\text { WOF }_{2} \text { (solid) }+\mathrm{H}_{2} \text { (gas) }
\end{gathered}
$$

This would result in $\mathrm{WO}_{2}$ or $\mathrm{WOF}_{2}$ being included in the deposited tungsten (Schroff-1971).

\section{Properties and Characteristics}

\section{Ductility}

The ductility of a CVD tungsten crucible will be crucial to withstanding the stresses of containing molten mctal, the molten salt system, and the stresses associated with thermal cycling.

Holman comments that CVD tungsten was not obtained with any greater ductility than other forms of tungsten. This condition occurs regardless of the purity of CVD tungsten or of its density, grain size, and heat treatment (Holman-1974).

Bryant notes that microscopic voids are found at grain boundaries in CVD tungsten, and that these voids retard grain boundary movement. This not only retards recrystallization but also prevents any gain in ductility. This condition can be compared to the reduced ductility of sintered tungsten versus sheet tungsten whereas the void volume of the sintered material causes a reduction in ductility. The voids formed at grain boundaries in CVD tungsten favor initiation of crack growth in these regions (Bryant-1977).

\section{Ductile-Brittle Transition Temperature}

Sherwood states that the DBTT of CVD tungsten from hydrogen reduction of $\mathrm{WF}_{6}$ occurs at temperatures 100 to $200^{\circ} \mathrm{C}$ higher than the DBTT of wrought powder metallurgy tungsten. This higher DBTT in CVD tungsten is due to the columnar grain structure, which is the preferred orientation (Sherwood). 
The DBTT of CVD tungsten from $\mathrm{WF}_{6}$ is lower than the DBTT of CVD tungsten from $\mathrm{WCl}_{6}$ since the material formed from hydrogen reduction of the chloride has a larger grain size.(Bryant-1975a). However, Bryant also says that CVD tungsten from the hydrogen reduction of $\mathrm{WCl}_{6}$ has excellent high-temperature ductility despite the large grain size $(579 \mathrm{~mm})$ (Bryant-1977).

\section{$\underline{\text { Grain Size }}$}

Though no conditions of the reaction are given, Glaski claims that pure CVD tungsten can now be deposited that has a grain size of 80,000 grains per square millimeter and is then stable above $2300^{\circ} \mathrm{C}$. He states that if the goal of 160,000 gralns per square millimetes could be dihieved, then CVD tungsten possibly would be ductile at room temperature (Glaski).

Lee reports that CVD tungsten, as first deposited, has a grain size of $9.9 \times 10^{-3} \mathrm{~mm}$, and this increases either to $14.8 \times 10^{-3} \mathrm{~mm}$ after a $24-\mathrm{hr}$ heat treatment at $1400^{\circ} \mathrm{C}$ or to $23.7 \times 10^{-3} \mathrm{~mm}$ after a 25 -hr heat treatment at $1600^{\circ} \mathrm{C}$. Grain size of deposits 0.05 in. away from the first deposit are considerably larger $-27.9 \times 10^{-3}$ millimeter. This grain size increases to $40.2 \times 10^{-3} \mathrm{~mm}$ after heat treatment of $25 \mathrm{hr}$ at $1600{ }^{\circ} \mathrm{C}$.

The $2 \%$ yield strength decreases from 105,000 to $82,000 \mathrm{psi}$ as the grain size increases from the fine to the coarse side (Lee).

\section{$\underline{\text { Structure and Grain Orientation }}$}

Chemical vapor deposition (CVD) tungsten has a preferential growth producing columnar grains that grow with a (100) crystallographic axis normal to the substrate. Associated "jagged" grain boundaries separate the columnar grains (Lundin). This columnar structure is not affected by temperature, pressure, or the hydrogen-to-tungsten $(\mathrm{F}, \mathrm{Cl}$, carbonyl) ratio (Schroff-1971).

Tungsten, formed by hydrogen reduction of tungsten hexafluoride, has a (100) fiber structure. Despite some grain growth, there is no loss in orientation after $2 \mathrm{hr}$ at $2100^{\circ} \mathrm{C}$ (Blocher).
The columnar grain structure of preferentially orientated tungsten is not conducive to high strength (Blocher).

Chemical vapor deposition tungsten is inferior to powder-metallurgy tungsten in ultimate tensile strength and in $0.2 \%$ offset yield strength. This probably is due to the columnar grain structure (Bryant-1977).

The following factors have an effect upon the grain structure and orientation: renucleation, recrystallization, adsorption of impurities, incorporation of gas-phase nucleated material, and co-deposition of a second-phase material. The nucleation and growth. kinetics of the deposit, and the resultant structure, are determined by supersaturation (which relates to the concentration of monomers on the surface) and temperature. The effects with varying supersaturation and temperature are shown in Table 11 (Blocher). The (110) fiber orientation can be obtained by hydrogen reduction of $\mathrm{WCl}_{6}$ near $1100^{\circ} \mathrm{C}$. The (111) orientation can be deposited at high hydrogen-to-tungsten hexafluoride $\left(\mathrm{H}_{2}: \mathrm{WF}_{6}\right)$ ratios of the reactant mixture (Blocher).

Impurities

Fluorine entrapped in CVD tungsten during the deposit has a marked influence on the properties of the deposit. This influence varies with the concentration of fluorine. Below 20-ppm fluorine, CVD tungsten is dimensionally stable. Above 20-ppm fluorine, dimensional changes increase with increasing fluorine content; the extent of change is dependent upon process temperature and time. Below 20-ppm fluorine, grain growth occurs during high-temperature heat treatments (Festa).

According to Glaski, interstitial fluorine levels below $10 \mathrm{ppm}$ in CVD tungsten will permit grain growth (Glaski).

Above 20-ppm fluorine, columnar grains of tungsten are more stable and, in general, the higher the fluorine content, the less amount of grain growth (Festa). 
TABLE 11. Effects of Supersaturation and Temperature on the Structure of Condensed Metals (Blocher)

\begin{tabular}{|c|c|}
\hline Effect of increased supersaturation & $\begin{array}{l}\text { Epitaxial growth } \\
\text { Platelets } \\
\text { Whiskers } \\
\text { Dendrites } \\
\text { Polycrystals } \\
\text { Fine-grained polycrystals } \\
\text { Amorphous deposits } \\
\text { Gas-phase nucleated snow }\end{array}$ \\
\hline
\end{tabular}

Glaski maintains that interstitial fluorine above about $25 \mathrm{ppm}$ produces voids in the grain boundaries

when the deposit is heated at $2000^{\circ} \mathrm{C}$ in a vacuum.

$\therefore$ He suggests the fluorine content should be maintained between 10 to $25 \mathrm{ppm}$ to stabilize the grain structure, but he admits the grains of CVD tungsten are still large (Glaski). The hardness of CVD tungsten increases with increasing fluorine content (Festa).

Festa states that the fluorine content is not reduced by high-temperature heat treatments in either a vacuum or argon and hydrogen atmospheres. $\mathrm{He}$ also remarks that high fluorine contents yield weld deposits that contain porosity, and that this porosity increases as the fluorine content increases (Fcsta).

Schroff indicates that low fluorine content in tungsten leads to thermal instability. He also says that absorbed molecules of fluorine or chlorine. influence the preferential crystal orientation (Schroff-1972).

Oxygen in the reactant mixture at 0.25 to $2.0 \mathrm{~mol} \%$ concentration can poison the reaction and reduce the amount of deposit at a deposition temperature of $530{ }^{\circ} \mathrm{C}$. It has less of an effect at $700{ }^{\circ} \mathrm{C}$ (Huegel).

Hydrogen chloride additions poison the reaction surface from 530 to $750{ }^{\circ} \mathrm{C}$ (deposition temperature) at a concentration of 0.25 to $2.0 \mathrm{~mol} \%$ and thereby reduces the deposition rate (Huegel, Holman-1974).

Water leakage into the reactant mixture also inhibits the reaction. Hydrogen fluoride appears to have little effect on the rate of deposition (Huegel).

\section{Additives}

Blocher states that further refinement of the grain structure of CVD tungsten and increased strength can be obtained by co-depositon of a material that causes renucleation (e.g., rhenium, carbon, hafnium, nitrate, or silicon) (Blocher). Holman researched the merits of a tungsten-rhenium (W-Re) alloy after deciding CVD tungsten has no ductility advantage over other forms. Tungsten-rhenium alloys can be deposited by simultaneous hydrogen reduction of a mixture of their fluorides $\left(\mathrm{WF}_{6}\right.$ and $\mathrm{ReF}_{6}$ ). Holman recommends an optimum $25 \%$ rhenium alloy concentration since greater rhenium additions result in an appearance of an equilibrium phase that embrittles the structure (IIolman-1974).

$\mathrm{A} \mathrm{SiH}_{4}, \mathrm{WF}_{6}$ reactant mixture can be used to produce a tungsten silicon coating alloy of varying percentages in which the silicon is in the body centered cubic tungsten structure. This alloy may be deposited at high rates and below $600^{\circ} \mathrm{F}$. The deposit is more resistant to thermal fatigue because of a fine grain structure (Haskell).

Slight oxygen additions (less than $20 \mathrm{ppm}$ ) to the tungsten deposit provide grain stability that possibly would require greater and uncontrollable levels of fluorine (Bryant-1975a).

Thorium oxide and zirconium oxide have been co-deposited with tungsten. Glaski reports that tungsten deposits with 1.8 to $2 \%$ thorium oxide have a fine, equiaxial grain structure of 60,000 grains per square millimeter and are void-free after being heated $5 \mathrm{hr}$ at $2000^{\circ} \mathrm{C}$. The ultimate tensile 
strength of these deposits are 115,000 to 150,000 psi at room temperature (Glaski).

\section{Bubbles}

Bubble or void formation in tungsten deposits should be held to a minimum to (1) prevent porosity that would contribute to seepage and (2) prevent embrittling through concentration of voids at the grain boundaries.

Schroff notes that bubble formation is related to the deposition temperature. He states that gas bubbles are formed upon annealing at $1400^{\circ} \mathrm{C}$ and above, if the deposition temperature, in kelvins, is below $30 \%$ of the melting point (Schroff-1971).

Schroff also claims that the number of small voids or bubbles increase with an increasing $\mathrm{H}_{2}$-to-WF 6 ratio, or with increasing total pressure of the reactant mixture; the number of bubbles decreases with increasing deposition temperature. With any bubble, motion is random unless there is a temperature gradient. Bubble-free coatings can then be obtained at a $\mathrm{H}_{2}$-to- $\mathrm{WF}_{6}$ ratio of $3: 6$, low pressures (below 20 torr), and at relatively high temperatures (above $700^{\circ} \mathrm{C}$ ) (Schroff-1971).

\section{Techniques}

\section{Deposition Conditions}

Tungsten Deposits - Schroff lists the main parameters in obtaining a sound tungsten deposit: substrate temperature, partial pressure of the reactant gas mixture, and the $\mathrm{H}_{2}$-to- $-\mathrm{WF}_{6}$ ratio. These parameters influence the deposition rate, the crystal structure and size, the amount of impurities, and the number of entrained microbubbles that form at the grain boundaries and then grow during the annealing process (Schroff-1971).

In commenting about the substrate temperature, Shim states that the growth rate and roughness of the growth surface increases with increasing temperature. Generally, decreasing the substrate temperature leads to higher yield strength, fluorine content, dislocation density, and microhardness while resulting in a lower (100) fiber texture. As an example, material grown at $500^{\circ} \mathrm{C}$ fractures on a finer scale and shows more resistance to slip and subsidiary cracking than material grown at $700{ }^{\circ} \mathrm{C}$ (Shim).

Schroff's comments on reaction conditions were as follows:

1. The deposition rate increases as the working pressure increases, reaching a maximum at 100 torr.

2. The lowest temperature at which the deposition rate is reasonable, decreases as the $\mathrm{H}_{2}$-to$\mathrm{WF}_{6}$ ratio increases.

3. As the $\mathrm{H}_{2}$-to- $\mathrm{WF}_{6}$ ratio increases, it is more difficult to produce adherent and homogeneous coatings at high temperatures because of nucleation in the vapor phase. The same condition is applicable when the pressure is increased at a given $\mathrm{H}_{2}$-to-WF $\mathrm{W}_{6}$ ratio.

4. For a constant $\mathrm{H}_{2}$-to- $-\mathrm{WF}_{6}$ ratio, the reaction efficiency increases as the total gas flow rate decreases. For varying $\mathrm{H}_{2}-$ to $^{-} \mathrm{WF}_{6}$ ratios, the optimum efficiency increases as the total flow rate increases.

5. Conditions that minimize the fluorine content are high work temperatures, high $\mathrm{H}_{2}$-to- $\mathrm{WF}_{6}$ ratios, low pressure, and the exclusion of oxygen or moisture from the system (Schroff1972).

Holman states that smooth deposits with void-free microstructures are produced with the following reaction conditions:

$$
\begin{array}{r}
\text { Pressure }--400 \text { to } 500 \text { torr } \\
\text { Temperature }--500 \text { to } 550^{\circ} \mathrm{C} \\
\text { Hydrogen flow }--740 \mathrm{~cm}^{3} / \mathrm{min} \\
\mathrm{WF}_{6} \text { flow }--83 \mathrm{~cm}^{3} / \mathrm{min}
\end{array}
$$

Holman believes that fully dense, strong tungsten deposits generally are obtained only when the deposition rate is surface-controlled, and that this then produces stable, cooperative growth of columnar crystals with preferred orientation. The 
reaction is surface-controlled when gas-phase diffusion is fast relative to the slowest process occurring on the surface (Holman-1974).

Federer states that the deposit with the lowest amount of hydrogen had no grown-in porosity; there was more porosity at $\mathrm{H}_{2}$-to- $\mathrm{WF}_{6}$ ratios of 3 and 5 . He also states that the fluorine content decreases with an increasing total gas flow rate (Federer-1972).

McKnight says reduced pressure of reactant gases aids in purging, and avoids impurity entrapment in the coating (McKnight).

Tungsten-Rhenium Alloy Deposits - Roberts claims that without brushing, a fine-grained, equiaxed structure may be obtained in alloy deposits. During deposition of a tungsten alloy with greater than $20 \%$ rhenium content, a metastable phase forms. Controlled dispersion of this phase is the key to fine-grain deposits.

The following conditions control the dispersion:

$$
\begin{gathered}
\text { Temperature }-600^{\circ} \mathrm{C} \\
\text { Pressure }--40 \text { torr } \\
\text { Hydrogen flow }--500 \mathrm{~cm}^{3} / \mathrm{min} \\
\mathrm{WF}_{6}\left(14.3 \% \mathrm{ReF}_{6}\right)--70 \mathrm{~cm}^{3} / \mathrm{min}
\end{gathered}
$$

A $25 \%$ rhenium deposit by this method had an ultimate tensile strength of $216,000 \mathrm{psi}$ and a yield strength of 213,500 psi (Roberts-1969).

Federer gives the following conditions in regard to deposition of tungsten rhenium alloys:

1. A minimum deposition temperature of about $750^{\circ} \mathrm{C}$ and a maximum pressure of about 10 torr was necessary for compositional uniformity.

2. $\mathrm{A} \mathrm{H}_{2}$-to- $-\mathrm{WF}_{6}+\mathrm{ReF}_{6}$ ratio of about 3 results in deposits of greater uniformity of thickness, smoother surface, and a finer grain structure than high ratios.

3. Conditions 1 and 2 also minimize nodular and porous microstructures.
4. Annealing studies showed that nominal $4 \%$ rhenium deposits had much greater grain stability than nominal 7 and $22 \%$ rhenium alloys.

5. The tungsten deposition rate increased with increasing pressure in the range of 10 to 100 torr, while the rhenium deposition was insensitive to pressure.

6. Periodically reversing the direction of gas flow increases the uniformity of deposition thickness in addition to the uniformity of rhenium concentration.

7. Deposits were rhenium rich with respect to the gas mixture at 500 and $600^{\circ} \mathrm{C}$, but the deposits had the same rhenium content as the gas mixture at about $700^{\circ} \mathrm{C}$ (Federer-1971).

Annealing

Lundin notes that gas porosity develops in CVD tungsten during high-temperature annealing. Pores are nucleated from dissolved gases and lattice vacancies. During elevated temperature exposure, the pores then grow preferentially on the grain boundaries by diffusion processes. These pores also link to cause gross grain boundary fissuring and fracture during high-temperature stress-rupture tests (Lundin).

Holman comments that the metastable federite phasc of CVD tungsten-rhenium alloy is quite brittle but can be transformed to a strong and ductile, terminal, solid solution by heat treating above $1200^{\circ} \mathrm{C}$. This can result in a fine-yrain, equiaxed, single phase with a solid solution developing. This then results in strong $25 \%$ rhenium deposits with a yield strength of 250,000 psi (Holman-1974).

\section{Grain Refinement}

Blocher notes that brushing is most effective in grain refinement. Brushing refers to the process of mechanically contacting the coating surface with a tool such as a tungsten brush. This brushing technique refines the grain structure and raises 
the tensile strength of tungsten and tungsten-rhenium coatings to that level characteristic of wrought material. This mechanical contacting creates defects by local cold working and causes momentary interruption of the gaseous boundary layer through which reactants must diffuse. Both of these factors favor renucleation (Blocher).

Holman comments that brushing increases the nucleation rate, suppresses the development of columnar grains, and results in a fine-grain equiaxed structure. Also, brushing generates randomly oriented nuclei, perpetuates first-stage growth, and removes insipient nodules from the surface before they grow to a damaging size. However, excessive contact pressure during brushing can cause "rubbedin porosity" (Holman-1974).

Roberts states that brushing during deposition causes continuous nucleation of grains and suppresses a coarser columnar structure (Roberts-1969).

Another technique for producing a fine-grain CVD coating has been developed by Chemetal, a firm in Pacoima, California. Holzl stated that Chemetal has developed techniques for producing a fine-grain, tungsten-carbide structure by maintaining process temperatures of 300 to $400{ }^{\circ} \mathrm{C}$ in connection with an interrupted coating process. He expects this technology to apply to pure tungsten (Holzl).

\section{Chemical Vapor Deposited}

\section{Tungsten on Graphite Crucible}

Argonne National Laboratory had a CVD tungstencoated graphite crucible fabricated and evaluated it in a simulated service environment. The graphite substrate was fabricated to match the thermal expansion of the tungsten. The molten metals and salts were successfully contained in the crucible for $300 \mathrm{hr}$ and except for some spalling of the tungsten coating, the crucible was sound. This experiment proved the acceptability of CVD tungsten for this application providing spalling is avoided. The tungsten was applied at $700{ }^{\circ} \mathrm{C}$ by reducing tungsten hexafluoride with hydrogen until a 0.030-in. coating was obtained (Kyle-1972).

\section{Chemical Vapor Deposited}

Tungsten on Molybdenum Crucible

A trip was made to Lawrence Livermore Laboratories, Chemetal, and Ultramet, and the people contacted recommended CVD tungsten on molybdenum crucibles. Their recommendation was based on molybdenum being easier to form and join than tungsten and on the thermal expansion of molybdenum coming close to matching tungsten (Holman1978, Holzl, Kaplin). Holzl and Kaplin preferred molybdenum over graphite as a substrate. They doubted that graphite, with the same thermal expansion as tungsten, would be available in the two-foot-diameter by four-foot high size required for the full-size pyrochemical processing crucible.

\section{Welding}

\section{$\underline{\text { Electron Beam }}$}

Bryant notes that few pores exist in the electron beam welds of tungsten CVD from the fluoride. Most of these pores were at the grain boundaries lying in the heat affected zone. The results of heat-aging these welded samples are as follows:

1. Outgassing $\left(50 \mathrm{hr}\right.$ at $\left.1800^{\circ} \mathrm{C}\right)$. No perceptible change in the material was noted, but any porosity present was at the grain boundaries in the heat affected zone or the fusion zone.

2. Aging $\left(5000 \mathrm{hr}\right.$ at $\left.1540{ }^{\circ} \mathrm{C}\right)$. This did not alter the microstructure nor increase the incidence of porosity.

3. Aging $\left(5000 \mathrm{hr}\right.$ at $\left.1700^{\circ} \mathrm{C}\right)$. Minimal grain coarsening occurred outside the fusion zone.

Bryant does not show as favorable results with welded tungsten deposited from the hydrogen reduction of tungsten hexachloride. This material produced grain growth with aging at $1540^{\circ} \mathrm{C}$. Also, aging at $1700^{\circ} \mathrm{C}$ produced large pores throughout the specimen.

Bryant says that the DBTT behavior of longitudinal welds closely approximates that of unwelded material. But the DBTT in the transverse direction is higher because of weld centerline fractures (Bryant-1975b). 


\section{Fusion Welding}

Lundin suggests fusion welding as the most satisfactory method of joining CVD tungsten. Highlights of his results follow.

\section{Heat Affected Zone -}

1. Pore formation occurs at grain boundaries. These pores then pin boundaries, thus preventing grain growth.

2. Pores on grain boundaries in the heat affected zone can link up and form continuous fissures.

\section{Fusion Zone -}

1. The incidence of grain boundary porosity is less in the fusion zone than in the heat affected zone, with no cases of grain boundary coalescence.

2. None of the pores in the fusion zone contributed to weld failure characteristics.

3. Three types of pore distribution exist in the fusion zone. Two types are from the precipitation of dissolved gases during solidification of the weld pool. The other type is a large-scale porosity caused by entrapment of gas pores that existed before melting occurred (Lundin).

\section{CONCLUSIONS}

This report summarizes a comprehensive literature search on tungsten fabrication. The report includes data that have been determined not to be directly applicable in fabricating pyrochemical processing hardware; it presents data that leave a better understanding of how manufacturers produce tungsten; and it gives aids for establishing fabricating practices Some of the data presented pertain directly to manufacturing necessary pyrochemical processing hardware.

According to the information pertaining directly to fabricating the pyrochemical processing crucibles, since wrought tungsten is available in widths less than 24 in., possible methods for fabricating a $10-\mathrm{ft}^{3}$ crucible are
1. Construct the crucible by brazing a drawn or spun bottom to a roll-formed and brazed tungsten sheet cylinder. Use a braze that flows at $1150^{\circ} \mathrm{C}$ or below to avoid recrystallized tungsten. Protect brazed joints from molten salt and molten metal by CVD coating with tungsten or by plasma-spray coating with tungsten.

2. Fabricate the crucible using a method similar to the brazing method but join the section with rivets. Seal the joints through CVD or plasma-spray rnating of tungsten.

3. Welding is not a viable joining option because it recrystallixes the tungsten at the joint. The result is a brittle joint and one that is more susceptable to corrosion.

4. Produce a free-standing, plasma-sprayed, tungsten crucible. Through nickel impregnation and low temperature sintering $\left(1300^{\circ} \mathrm{C}\right)$, . densify the plasma-sprayed structure to prevent leakage.

5. Chemical vapor deposit (CVD) tungsten on a molybdenum substrate. Choose molybdenum as a substrate because (a) there is a fair match in thermal expansion with tungsten, (b) molybdenum is easier to form and join than tungsten, and (c) molybdenum can react with tungsten to form a metallurgical bond.

Since the literature review shows that tungsten tubing cannot be drawn and is fabricated only in short lengths through machining, the necessary transfer tubes should be obtained by one of the following options:

1. Machine tubing from molybdenum $-30 \%$ tungsten alloy

2. Use drawn molybdenum tubc with a protective liner such as CVD tungsten

3. Plasma-spray tungsten tubes by the same method used to make free-standing, plasmasprayed tungsten crucibles. 


\section{REFERENCES}

ASM

American Society for Metals, "Properties and Selection of Metals," Metals Handbook, Vol 1; 8th Edition, 1961.

AWS

American Welding Society, Brazing Manual, 3rd Edition, (Rev.) 1976.

Baciarelli

R. M. Baciarelli, "Refractory Metals Brazed for Operation at $2200^{\circ}$ F," Metal Progress, pp 189192, May 1967.

Bacigalupi

R. J. Bacigalupi, "Fabrication and Evaluation of Chemically Vapor Deposited Tungsten Heat Pipe," Lew's Research Center, 1972. Proceedings from the Third International Conference on Chemical Vapor Deposition, April 1972.

Barr

R. Q. Barr and D. J. Klaphaak, "Effect of Molybdenum on the Grain Size and Workability of Arc-Cast Tungsten," Met. Soc. Conf., Vol 41, pp 727-735, 1967 (See Conf-651025 Vol I).

\section{Barto}

R. Barto, Amax Specialty Metals, personal communications, 1978.

Bauer

D. W. Bauer, $A$ Comparative Evaluation of the Formability of Tungsten Plate and Sheet by Spinning Techniques, Navy Contract No. NOw 63-0542c, Super Temp Corporation, Santa Fe Springs, California, Quarterly Report No. 3, p 20, August 1964.

Bechtold

J. H. Bechtold and P. G. Shewmon, "Flow and Fracture Characteristics of Annealed Tungsten," Trurssuctions of the ASM, Vol 46, pp 397-408, 1954.

Bennett-1962

G. A. Bennett, P. A. Nelson, L. F. Dorsey, and W. A. Pehl, Solution Stability and Material Demonstration Runs, Argonne National Laboratory, Chemical Engineering Divisions Summary Report ANL-7477, March 1962.
Bennett-1963

G. A. Bennett, W. A. Pehl, and N. Quattropani, Testing of Plasma-Sprayed and Vapor Deposited Coating Materials, Argonne National Laboratory, Quarterly Report ANL-6725, April-June 1963.

Bennett-1964

G. A. Bennett, N. Quattropani, and W. A. Pehl, Testing of Plasma-Sprayed Tungsten Coatings, Argonne National Laboratory, Chemical Engineering Division Semiannual Report, ANL-6800, May 1964.

Bernard

J. Bernard, Thermo Electron Corporation, personal communication, 1978.

Blocher

J. M. Blocher, "Structure/Property/Process Relationships in CVD," Vac. Sci. Technol., Vol 11, No. 4, July-August 1974.

Bobrov

G. V. Bobrov, "Strengthening of Sprayed Coatings by Brazing," Welding Production, Vol 8, pp 3436, 1974.

Boulger. F. W. Boulger, H. J. Henning, and D. E. Strohecker, Metal Deformation Processing, Vol $I I-$ Shear Forming and Spinning Metals, Defense Metals Information Center, Report No. 226, pp 49-66, July 7, 1966.

Brunst

W. Brunst, Plasmatechnologie des Wolframs, Schweissen und Schneiden, Vol 5, No. 18, pp 239-240 (in German), 1966.

Bryant-1975a

W. A. Bryant and R. E. Gold, "Weldability of Three Forms of Chemically Vapor Deposited Tungsten," Welding Research Supplement; November 1975.

Bryant-1975b

W. A. Bryant and R. E. Gold, "Weldability of Three Forms of Chemically Vapor Deposited Tungsten," Welding Journal, pp 405s-408s, Noveninber 19.75.

Bryant-1977

W. A. Bryant, "Chemically Vapor Deposited Tungsten; Its High Temperature Strength and 
Ducitlity," Journal of Less-Common Metals, Vol 53, pp 34-42, 1977.

Burk

J. Burk, product engineer at GTE Sylvania, personal communications, 1978.

\section{Bydash}

F. Bydash, Schwartzkolp Development Corporation, (representatives in USA of Metallwerk Plansee), personal communications, 1978.

\section{Chun}

J. S. Chun and J. G. Byme, The Mechanical Properties of Annealed Chemical Vapor Deposited Tungsten, Univ. of Utah, Proceedings, The Third International Conference on Chemical Vapor Deposition, April 1972.

\section{Cole}

N. C. Cole, R. G. Gilliland, and G. N. Slaughter, "Weldability of Tungsten and Its Alloys," Welding Journal, pp 419s-426s, September 1971 .

\section{Collins}

L. W. Collins, Jr., "Part 2 Basic Data for Shear Spinning," Machinery, pp 94-98, November 1963.

\section{Cowan}

R. E. Cowan, S. D. Stoddard, and C. C. Herrick, "Mechanism of Tungsten Adherence to Bodies Containing Yttria," American Ceramic Society, Fall Meeting, September 17, 1964.

\section{Crimmins}

P. O. Crimmins and C. W. Heimlich, "Spinning of Refractory Alloyș," Metal Progress, pp 67-72, December 1962.

\section{D'Annessa}

A. T. D'Annessa, "Diffusion Bonding Beryllium, Molybdenum and Tungsten," Metal Progress, pp 71-74, February 1967.

\section{Dorodnyi}

B. A. Dorodnyi, A. M. Grinberg, I. S. Kainarskii, E. V. Degtyareva, and I. G. Orlova, "Hydrostatic Molding of Large Refractory Products," Ukraniun Scientific-Research Institute for Refractories, pp 17-19, January 1976.
Farrell

K. Farrell, J. T. Houston, and J. W. Chumley, "Hot Cracking in Fusion Welds in Tungsten," Welding Journal, Vol 49, No. 3, pp 132s-137s, March 1970.

\section{Federer-1971}

J. L. Federer, K. W. Hatt, W. R. Martin, and D. W. Ramey, Chemical Vapor Deposited Refractory Metal Capsules for Radioisotope Sources, ORNL-TM-3608, Oak Ridge National Laboratory, 1971.

Federer-1972

J. L. Federer and A. C. Schaffhauser, Chemical Vapor Deposition and Characterization of Tungsten-Rhenium Alloys, Oak Ridge National Laboratory, 1972.

Festa

J. V. Festa and J. C. Danko, Some Effects of Fluorine Content on the Properties of Chemically Vapor Deposited Tungsten, G. E. Company, Nuclear Thermionic Power Operation.

Proceedings of the Conference of Chemical Vapor Deposition of Refractory Metals, Alloys, and Compounds, September 1967.

Fusco

R. S. Fusco, "The Influence of Stress. Relieving on Tungsten Sheet," GE Refractory Metals, June 1967.

German

R. M. German and V. Ham, "The Effect on Nickel and Palladium Additions on the Activated Sintering of Tungsten," The International Journal of Powder Metallurgy and Powder Technology, Vol 12, No. 2, April 1976.

Gilliland-1966a

R. G. Gilliland, Joining of Tungsten, Oak Ridge National.Laboratory Report, ORNL-TM-1606, October 1966.

Gilliland-1966b

R. G. Gilliland, "Brazing Alloys for Refractory Metals," U.S. Patent 3293741, December 27, 1966.

\section{Glaski}

F. A. Glaski, A Report on the Current Role of Chemical Vapor Deposition as a Manufacturing 
Process, San Fernando Laboratories. Proceedings of the Conference of Chemical Vapor Deposition of Refractory Metals, Alloys, and Compounds, September 1967.

Googin

J. M. Googin, H. T. Greene, G. R. Guinn, and A. C. Neeley, Tungsten Powder Metallurgy in the Production of Large Crucibles and Susceptors, Union Carbide Corporation, April 1965.

Grishin

V. L. Grishin, "New Brazing Alloy VPr 20 for Brazing .High-Melting Materials," Svarochnoe Proizvodstvo, Vol 9, p 48, (in Russian), 1976.

Grosvenor

D. E. Grosvenor, I. O. Winsch, W. E. Miller, G. J. Bernstein, and R. D. Pierce, Design and Application of Corrosion-Resistant Heated Transfer Tubes for Liquid Metals and Salts, Argonne National Laboratory, ANL-7522, p 15, December 1968.

Haegland

B. F. Haegland, B. Eftestol, and K. Schriener, Explosive Hot Forming of Steels and Refractory Metals, Paper from High Energy Rate Working of Metals, Vol 1, pp 160-168, 1964.

Hargrave

D. P. Hargrave, "Molybdenum and Tungsten," Proc. Instn. Mech. Engrs., pp 38-48, 1965-66.

Haskell

R. W. Haskell and A. R. Iman, Chemically Vapor Deposited Tungsten Coatings for Erosion Protection, AD-A026 039, U. S. Dept. of Commerce, 1976.

Haynes

C. W. Haynes, Development of Low Temperature Brazing of Tungsten for High Temperature Service, Final report No. RDT 1249-6, U.S. Navy Bureau of Ships, Contract NOw 61-0414, AD-274-616, March 26, 1972.

Hegedus

A. K. Hegedus and R. S. Fusco, "The Influence of Stress Relieving on Optimum Quality Tungsten Sheet," Met. Soc. Conf., Vol 41, pp 727-735, 1967, (See Conf-651025 Vol I).
Hershenson

L. H. Hershenson, "Method of Joining Certain Metals," U.S. Patent 3657801, April 25, 1972.

Holman-1967

W. R. Holman and F. V. Huegel, "CVD and Tungsten-Rhenium Alloys for Structural Applications," Proceedings of the Conference on Chemical Vapor Deposition of Refractory Metals, Alloys, and Compounds, September 1967.

Holman-1974

W. R. Holman and F. V. Huegel, "Interrelationships Between Process Parameters, Structure, and Properties of CVD Tungsten, and TungstenRhenium Alloys," J. Vac. Sci. Technol., Vol 11, No. 4, July-August 1974.

Holman-1978

Personal communications between W. R. Holman, Lawrence Livermore Laboratory and R. Corle and G. Mah of Rockwell International, Rocky Flats Plant, 1978.

Holzl

R. Holzl, personal communications between

R. Holze, Chemetal, Pacoima, California and R. Corle and G. Mah of Rockwell International, Rocky Flats Plant, 1978.

Hovis, Jr.

V. M. Hovis, Jr., Coating of Surfaces by Plasma Spraying, Union:Carbide, Y-12 Plant Report YDA-7012, March 1977.

Huegel

F. V. Huegel, E. Fung, H. Cheung, and W. R. Holman, "Effect's of Additives on the Deposition Rate of CVD Tungsten," University of California, Proceedings, the Third International Conference. on Chemical Vapor Deposition, April 1972.

Interatom

"Verfahren zum Metallisieren einer SauerstoffIonen Leitenden Keramik mit Wolfram, Molydaen oder Niob," German Patent 2350466, (in German), April 24, 1975.

İsserow

S. Isserow, R. G. Jenkins, J. G. Hunt, and G. I. Friedman, "Fabrication of Tungsten and Tungsten - 25\% Rhenium Tubing," Nuclear Applications, Vol 2, pp 304-307, August 1966. 
Jaffee

R. I. Jaffee, D. J. Maykuth, and W. D. Barth, Fabrication of Tungsten for Solid-Propellant Rocket Nozzles, Defense Metals Information Center, Battelle Memorial Institute, DMIC Memo 136, November 2, 1961.

Japka

J. E. Japka and G. S. Hoppin, III, "Shear Forming of Tungsten," Metals Engineering Quarterly, pp 38-46, August 1962.

Kaplin

R. Kaplin, personal communications between R. Kaplin, Ultramet, Pacoima, California, and R. Corle and G. Mah of Rockwell International, Rocky Flats Plant, 1978.

Keith

G. H. Keith, J. S. Winston, and H. G. Iverson, Evaluation of Electrowon Tungsten Sheet, U.S. Dept. of Interior, Bureau of Mines, 1970.

Kitahara

S. Kitahara and A. Hasui, "A Study on the Bonding Mechanism of Sprayed Coatings," J. Vac. Sci. Technol., Vol II, No. 4, pp 747-753, JulyAugust, 1974.

Kyle-1969

M. L. Kyle, R. D. Pierce, and V. M. Kolba, "Containment Materials for Pyrochemical Processes," Symposium on Reprocessing of Nuclear Fuels, USAEC Report CONF-690801, Ames, Iowa, pp 433-452, 1969.

Kyle-1972

M. L. Kyle, V. M. Kolba, and R. D. Pierce, "Evaluation of a CVD Tungsten-Graphite Crucible," in Proc. of the 3rd International Conference on Chemical Vapor Deposition, ed. by F. A. Glaski, University of Utah, College of Engineering, Div. of Materials Science and Engineering, Salt Lake City, pp 614-618, 1972.

Leber

S. Leber, J. Tavernelli, D. D. White, and R. F. Heheman, "Fracture Modes in Tungsten Wire," Journal of the Less Common Metals, Vol 48, pp 119-133, 1976.

\section{Lee}

H. B. Lee and J. S. Chun, "The Mechanical

Behavior of CVD Tungsten at Low Temperatures,"
University of Utah, Proceeding, The Third International Conference on Chemical Vapor Depositior. April 1972.

Lessman

G. G. Lessman and R. E. Gold, "The Weldability of Tungsten Base Alloys," Welding Journal, pp 528s-542s, December 1969.

Lundin

C. D. Lundin and K. Farrell, "Distribution and Effects of Gas Porosity in Welds in CVD Tungston," W'elding Jouriul, Vü 49, Nu. 10, pp 461s-464s, October 1970.

Marshall-1967a

J. C. Marshall, J. A. McGurty, and G. Korton, "Refractory Metal Brazing Product and Process," U.S. Patent 3316069, April 25, 1967.

Marshall-1967b

J. C. Marshall and H. G. Smith, "Brazing Alloys for Tungsten and Molybdenum," U.S. Patent 3312539, April 4, 1967.

Marshall-1968

J. C. Marshall, "High Temperature Brazing Alloys for Tungsten and Tantalum and Alloys Thereof," U.S. Patent 3374092, March 19, 1968.

Martin

W. R. Martin, R. L. Heestand, R. E. McDonald, and G. A. Reimann, Application of Chemical Vapor Deposition to the Production of Tungsten Tubing, Metals and Ceramics Division, Oak Ridge National Laboratory, Proceedings of the Conference on Chemical Vapor Deposition of Refractory Metals, Alloys, and Compounds, September 1967.

Mash

D. R. Mash, D. W. Bauer, and M. Schnassler, "Fabricating the Refractory Metals," Metal Progress, pp 89-94, February 1971; pp 60-66, March 1971; pp 99-112, April 1971.

Mayfield

R. M. Mayfield and W. R. Burt, Jr., Development of Techniques of Fabrication and Testing-Fabrication of Tungsten and TungstenAlloy Tubing, Argonne National Laboratory, ANL 9299, pp 173-197, 1966. 
Maykuth

P. J. Maykuth, Summary of Contractor Results in Support of the Refractory Metals Sheet Rolling Program, Defense Metals Information Center, Battelle Memorial Institute, DMIC Report 231, December 1, 1966.

\section{McKnight}

H. H. McKnight, "Vapor Phase Forming," Mechanical Engineering, pp 42-45, February 1969.

\section{Mechelburg}

V. E. Mechelburg, "Wolfram-Einsatzbereiche, Eigenschaften, Bearbeitungs-verfahren," Technica, Vol 17, pp 1091-1095, (in German), 1978.

\section{Medzyanovskiy}

Medzyanovskiy, "An Experiment in the Explosive Forming of Refractory Metals," KuznechnoShtampovochnde Proizvodstvo, Vol 2, pp 25-27, February 1969.

\section{Metallwerk Plansee} Metallwerk Plansee, "Tungsten," Supplier Catalog, Metallwerk Plansee, Austria, p 30, December 1978.

Metals Handbook Metals Handbook, "Forming," Forming Refractory Metals, Vol 4, pp 276-378, 1969.

\section{Metcalfe}

A. G. Metcalfe, "Reactive Brazing--A New Joining Method," Metal Progress, pp 83-86, May 1963.

\section{Moorhead}

A. J. Moorhead, J. R. Distefano, and R: E. McDonald, "Fabrication Procedures for Unalloyed Molybdenum," Nuclear Technology, Vol 24, pp 50-63, October 1974.

\section{Nelson}

S. G. Nelson, "Special Fabrication Techniques," Reactor Materials, Vol 11, No. 3, pp 191-203, Fall 1968.

Nerodenko

M. M. Nerodenko et al., "Special Features of the Welding of Sintered Tungsten," Automatic Welding, Vol 4, pp 54-55, 1976.
Parks

J. W. Parks, "Tungsten-The Versatile Heavy," Precious Metal, pp 44-45, December 1972.

Pattee-1973

H. E. Pattee, "High-Temperature Brazing," WRC Bulletin 187, Welding Research Council, September 1973.

Pattee-1974

H. E. Pattee, "High-Temperature Brazing," WRC Bulletin, Welding Research Council, New York, pp 37-45, 1974.

Raab

B. Raab and A. Schock, "Electron Beam Welding of Tungsten to Tungsten/Rhenium and Tungsten/ Rhenium to Niobium," paper presented at 1970 Thermionic Conversion Specialists Conference, Miami, Florida, from CONF-70-10-39, October 26-29, 1970.

Robbins

W. P. Robbins, Brazing Superalloys and Refractory Metals, MLM-1322, Mound Laboratory, Miamisburg, Ohio, March 10, 1967.

Roberts-1969

L. W. Roberts, "The Properties of CVD Deposits of W and W-Re Alloys," High Temperature Materials, 1969.

Roberts-1971

P. M. Roberts, "Brazing Precious and Refractory Metals," Metal Construction and British Welding Journal, pp 118-123, March 1971.

Schmidt

F. F. Schmidt and E. S. Bartlett, "The Mechanical Behavior of Refractory-Metal Alloys," Metal Treating, Vol 18, No. 2, 1967.

\section{Schwartz}

M. M. Schwartz, "Clean, Fast Vacuum Brazing Joins Diverse Materials," Materials Engineering, pp 76-78, December 1967.

Semchyshen

M. Semchyshen, E. Kalns, D. J. Klaphaak, and R. Q. Barr, Development of High Strength Molybdenum and Tungsten Base Alloys, Climax Molybdenum Company of Michigan, 1966. 
Sherwood

P. J. Sherwood, "The Relation Between the Mechanical Properties and the Microstructure of Chemically Vapor Deposited (CVD) Tungsten and Rhenium," Rocket Propulsion Establishment, England, Proceedings, The Third International Conference on Chemical Vapor Deposition, April 1972.

\section{Shim}

H. S. Shim, R. W. Haskell, and J. G. Byme, "Studies of Substrate Effects on the Chemical Vapor Deposition of Tungsten," University of Utah, Proceedings, The Third International Conference on Chemical Vapor Deposition, April 1972.

\section{Schroff-1971}

A. M. Schroff and G. Delval, "Recent Developments in the Chemical Vapor Deposition of Tungsten and Molybdenum," High TemperaturesHigh Pressures, Vol 3, 1971.

Schroff-1972

A. M. Schroff, "Influence of the Pressure on the Deposition Characteristics of CVD Tungsten," Proceedings, The Third International Conference on Chemical Vapor Deposition, April 1972.

\section{Slaughter}

G. M. Slaughter, "Welding and Brazing of Refractory Metals," Society of Automotive Engineers, 1961 SAE National Aeronautic Meeting, New York, paper 304E.

\section{Smith}

G. T. Smith, Oak Ridge National Laboratory, personal contact to obtain drawing procedure on tungsten, 1978.

\section{St. Germain}

F. St. Germain, Evaluation of RMSP Tungsten Sheet, Quarterly Progress Report 5, Project 3478-62, U.S. Navy Bureau of Naval Weapons, Contract NOw 63-0786d, AD-607605, October 15, 1964.

\section{Stack}

E. A. Stack, "Forming Exotic Materials by the Use of High Pressure Hydraulics," American
Society of Tool and Manufacturing Engineers, technical paper SP65-127, 27 pages, 1965.

\section{Stoder}

S. Stoder, Los Alamos Scientific Laboratory, personal communications, 1978.

Syre

R. Syre, Handbook on the Properties of Niobium, Molybdenum, Tungsten, Tantalum, and Some of the Alloys, AGAROGRAPH-94, report AD476420, p 302, May 1965.

Taylor

T. A. Taylor, Technical Note No. 78-74, Material Development-Technology Coatings Service Department, Linde Division, Indianapolis, Indiana, p 9, October 9, 1978.

\section{USAEC-1967}

United States Atomic Energy Commission, "Brazing Alloys for Tungsten, Molybdenum, and Alloys Thereof," British Patent 1063274 , March 30, 1967.

USAEC-1968

United States Atomic Energy Commission, "High Temperature Brazing Alloys for Tungsten and Tantalúm," British Patent 1136980, December 1968.

Webster

T. H. Webster and L. Eyre, "Improvements in or Relating to the Ductility of Group VIA Metals and Base Alloys Thereof," British Patent 1411781 , October 29, 1975.

Wick

C. Wick, "Spinning, a Review and Update," Manufacturing Engineering, pp 73-77, January 1978.

Wilkinson-1969

W. D. Wilkinson, "Properties of Refractory Metals," Tungsten-Group Metals and Alloys, Chapter 7, pp 245-300, Gordon and Breach Science Publishers Inc., New York, 1969.

Wilkinson-1970

W. D. Wilkinson, "Fabrication of Refractory Metals," Tungsten, Chapter 8, pp 297-300, Gordon and Breach Science Publishers Inc., New York, 1970. 


\section{Wilson}

R. W. Wilson, "Chemical Vapor Deposition-Below the Recrystallization Temperatures," Welding Journal, Vol 8, No. 8, pp 345s-354s, August 1968.

Winsch

I. O. Winsch, M. L. Kyle, R. D. Pierce, and L. Burris, Jr., Tungsten Crucibles in Pyrochemical Processing of Nuclear Fuels, Nuclear. Application, Vol 3; April 1967.

\section{Wolkoff}

J. Wolkoff and R. E. Nowak, Evaluation on Tungsten Coatings of Various Materials, ANL6477, Argonne National Laboratory, March 1962.

Young

W. R. Young and E. S. Jones, Joining of Refractory Metals by Welding and Brazing. Technical Documentary Report No. ASD-TDR-63-88. Air Force Systems Command, Wright-Patterson Air Force Base, Ohio, January 1963. 
RFP-2864

音

严

妾 